\title{
Close up to the surface: reflections on a preliminary forensic study of four Chinese bronze mirrors
}

Jiafang Liang ${ }^{1}$ and Quentin Parker $2,3^{*}$ (i)

\begin{abstract}
This article presents a generic, objective and evidence based forensic study of 4 very different Chinese bronze mirrors. The work was done within the Architectural Conservation Laboratory (ACLab), the Department of Physics, the Faculty of Medicine and also the Planetary Spectroscopy and Mineralogy Laboratory (PSML) all at the University of Hong Kong. The mirrors nominally cover the period of the Warring States (475-221 BC), Han (206 BC to 220 AD) and later Song (960-1279AD) dynasties. Comprehensive, mostly non-invasive, analytical methods and techniques were used. These included surface microscopy of tool marks, patina, corrosion and any residual archaeological evidence. Ultraviolet radiation examination, chemical spot testing and polarised light microscopy of ground-up patina samples was also done. More sophisticated "pXRF" X-ray fluorescence, "MARS" tomographic X-ray scanning and infrared spectroscopic analysis of the bronze alloys, corrosions and any earthen encrustations were also performed. This was to uncover as much forensic evidence as possible for these unprovenanced bronze mirrors. The results have revealed key metallurgical information of those four mirrors along with surface patina morphology and details of the corrosion and residual surface archaeology. A database on the physical condition of these mirrors has been established and burial/treatment history revealed. Mirrors 1 and 2 appear to have been heavily cleaned, polished and treated with abrasives in modern times. Mirror 2 in particular, has some problematic corrosion and inconclusive alloy composition. Mirror 3 and 4 both have archaeological evidence and no contrary forensic data that questions authenticity. Forensic study and verification of objects and artworks for academic purposes remains a legitimate and vital undertaking for universities, museums and national collections across the globe. Hence, the issue of authenticity when archaeological context is lacking is discussed. However, our key aim is to establish what can be learnt from technological, forensic investigation when studying bronze mirrors without further context and records, and what firm, generic evidence can be extracted from such close forensic examination to shed light on their true nature. We hope this will be useful for other researchers.
\end{abstract}

Keywords: Forensic study, Chinese bronze mirrors, Copper alloy

\section{Introduction}

Chinese bronze mirrors from antiquity, in all their variety and forms, are valued cultural heritage items. Provenance in most cases is sparse. The exceptions are for well documented cases from certified excavations where proper

\footnotetext{
*Correspondence: quentinp@hku.hk

2 Physics Department, Faculty of Science, CYM Physics Building, The

University of Hong Kong, Hong Kong, SAR, China

Full list of author information is available at the end of the article
}

archaeology is possible or from mirrors from reputable collections where provenance usually relates to ownership history that may go back decades but may not of itself donate veracity. The archaeological detail, necessary for more meaningful and contextual historical evaluation, is normally missing in such cases. For such bronzes, undertaking a proper technical and scientific evaluation with respect to issues such as metallurgy, corrosion, encrustations, wear and tear, repairs, cleaning and any trace archaeology is key. It can provide valuable insights
Springer Open

(c) The Author(s) 2021. This article is licensed under a Creative Commons Attribution 4.0 International License, which permits use, sharing, adaptation, distribution and reproduction in any medium or format, as long as you give appropriate credit to the original author(s) and the source, provide a link to the Creative Commons licence, and indicate if changes were made. The images or other third party material in this article are included in the article's Creative Commons licence, unless indicated otherwise in a credit line to the material. If material is not included in the article's Creative Commons licence and your intended use is not permitted by statutory regulation or exceeds the permitted use, you will need to obtain permission directly from the copyright holder. To view a copy of this licence, visit http://creativeco mmons.org/licenses/by/4.0/. The Creative Commons Public Domain Dedication waiver (http://creativecommons.org/publicdomain/ zero/1.0/) applies to the data made available in this article, unless otherwise stated in a credit line to the data. 
into the true nature of the objects and provide useful clues to the likely history of such objects independent of any stylistic and typological design elements present.

\section{Overview: mirror history in China}

There are different opinions on where the first idea to make bronze mirrors by the ancient Chinese originated. Modern scholar Liang [1] thought the ancient Chinese got the inspiration of creating a reflective surface to see the world from looking at still water in a lake or pond. Gradually, bronze basins for water and later polished bronze plates were developed for reflection. The earliest recognisable Chinese bronze mirror was unearthed in Gansu Province and has been dated to the Neolithic period's Qijia culture. Over the subsequent 4000 years of history, Chinese bronze mirror design, technology and prominence experienced several important time periods including the three most important: the Warring States (475-221 BC), the Han (202 BC-220 AD) and the Tang (618-907).

The Warring States was a developing period of bronze mirror refinement, indicated by diverse artistic styles and delicate and intricate decoration. The Han dynasty was a period when the bronze mirror industry was flourishing as evidenced by the vast numbers of mirrors from this period that have come to light even if the execution of their designs were of lesser quality. In the Tang dynasty, in terms of shape, size, pattern and various decoration techniques such as with lacquer and mother of pearl, bronze mirrors were much more varied and sophisticated but again the surface precision and fineness does not match the excellence of the Warring States. The Song dynasty (960-1279 AD) was the most varied in terms of mirror shape, even if design was typically very simple. This opinion is based on the distinctive characteristics, artistic design and material quality and the numbers of surviving examples from these periods. The bronze mirror industry also started to decline in this period as indicated by the significantly less numbers uncovered via archaeological excavations and the more simple designs compared to the preceeding Tang dynasty [2]. Some scholars believe this decline during the Song is related to wars and a reduction of copper mining. However, Zhang [3] considers the reason for the lack of even basic decoration on Song mirrors is the result of the prevalance of adopting a 'simple life' philosophy at that time.

\section{Mirror casting}

In China, bronze mirrors were manufactured via the commonly adopted clay mould casting technique. The model, together with desired inscribed decoration, was made first and the mould was second [3, p. 32]. An archaeological excavation of a mirror workshop dated to the Western Han dynasty in Shandong province, P. R. China [4] proved this practice was employed. Before clay moulds, stone moulds were used [5]. There is no evidence found to indicate that the lost wax technique was used by the ancient Chinese to make bronze mirrors, perhaps due to the simple, monolithic forms.

\section{Chinese mirror alloys}

Like other ancient bronzes, a bronze mirror is an alloy that contains various major fractions of copper, tin and lead and then trace elements. Although historic records did not specifically mention lead in their formulae, lead is commonly detected. According to the "six formulae: for making bronze for different uses given in K'ao Kung Chi 考工记 by Tai Chen, the ratio for making mirrors and specula is $50 \%$ Copper and $50 \%$ tin. However, this 50:50 ratio is not observed in extant studied mirrors based on modern scientific appraisal and metallurgical analysis. Table 1 lists published percentage abundances of the major elements copper, tin and lead found in Chinese bronze mirrors dated to the Warring States, Han dynasty and Song-Jin periods in particular that we have compiled via an extensive literature search.

No quantitative error estimations or sigma dispersions on these averages have been provided, despite the precise percentages reported in the literature. However, accuracy at the few percent level only can be safely assumed. Basically, the copper fraction ranges from 65 to $80 \%$. Some cases with an unusually low percentage of a given metal can occur, usually due to the chosen testing location on an area with high corrosion which can concentrate lead and tin in the corrosion. Also non-invasive assay techniques are used that provide only surface composition information. The content of tin and lead with respect to copper has also varied considerably throughout the history of Chinese bronze mirror manufacture. From Table 1 it can be seen that the ratio of tin reduced with time while lead increased. The changes of the observed tin-lead ratio also affects the hardness and polishing properties of the mirror. The usual high tin content for mirrors compared to other typical Chinese bronze artifacts (such as sacrificial cooking vessels and ornaments) yields an alloy that is hard and brittle. However, it provides a silvery-white colour, well suited to enabling a very good polish and hence an excellent reflective surface for a mirror. The degree of mirror corrosion can reflect not only differences that basic elemental composition produces but also the effects of soil and moisture content during a long burial history.

In terms of trace elements the varying zinc fractions found in mirrors from the Han and Song-Jin dynasties likely reflect contamination by this element in the base ores used and available at these times. Zinc has a much 
Table 1 Key references on the major elemental composition of ancient Chinse bronze mirrors

\begin{tabular}{|c|c|c|c|c|c|}
\hline Dated period & $\mathrm{Cu} / \mathrm{Sn} / \mathrm{Pb}(\%)$ & Analytical equipment & Reference & Year & No. mirror and Site location \\
\hline \multirow[t]{5}{*}{ The Warring States } & Ave. 68.05/21.70/3.53 & Not provided & [7, Table 9] & 1961 & $\begin{array}{l}3 \text { mirrors } \\
\text { Unknown location }\end{array}$ \\
\hline & $\begin{array}{l}71.74 / 19.62 / 2.69 \\
66.33 / 21.99 / 3.63\end{array}$ & Not provided & {$[9$, p. 55] } & 1984 & 2 mirrors-Hu nan \\
\hline & $70 / 25 / 4$ & Not provided & [6] & 1991 & In general \\
\hline & $\begin{array}{l}.151 / .726 / .114 \\
.200 / .705 / .085\end{array}$ & SEM & [27] & 1995 & $\begin{array}{l}2 \text { mirrors } \\
\text { Unknown location }\end{array}$ \\
\hline & $77.28-78.94 / 18.64-21.34 / 1.26-2.69$ & Not provided & {$[10$, p. 117] } & 2000 & 5 mirrors-Unknown locations \\
\hline The Late Warring States & Ave. 67.17/25.10/7.8 & EDS & [13] & 2015 & 23 mirrors-Lintong, Shaanxi \\
\hline \multirow[t]{10}{*}{ Han Dynasty } & $\begin{array}{l}\text { Early Han } \\
\text { ave. 67.14/24.14/5.43 } \\
\text { Han ave. 67.07/25.42/4.47 } \\
\text { Late Han ave. 69.03/24.62/4.68 }\end{array}$ & & [7, Table 9] & 1961 & $\begin{array}{l}\text { Early Han- } 5 \text { mirrors } \\
\text { Han-35 mirrors } \\
\text { Late Han-3 mirrors } \\
\text { All unknown location }\end{array}$ \\
\hline & $67-69 / 23-24 / 4-6$ & Not provided & [9. P.114] & 1984 & $\begin{array}{l}14 \text { mirrors-unprovenanced; all } \\
\text { analysed by a Dr. Giichi Tanabe }\end{array}$ \\
\hline & $\begin{array}{l}\text { Cu: } 55.66-69.11 \\
\text { Sn: } 21.17-37.28 \\
\text { Pb: } 4.62-9.10 \\
\text { Cu: } 6.2 \\
\text { Sn: } 73.3 \\
\mathrm{~Pb}: 7.6\end{array}$ & $\begin{array}{l}\text { Wet chemistry } \\
\text { Scanning electron probe } \\
\text { on surface }\end{array}$ & [28] & 1988 & $\begin{array}{l}13 \text { mirrors for wet chemistry } \\
\text { Unknow locations } \\
\text { Unknown number and locations }\end{array}$ \\
\hline & $\begin{array}{l}\text { Western Han } \\
\text { 67.13-74.60/20.23-26.74/1.23-6.00 } \\
\text { Middle Han } \\
\text { 68.23-68.87/23.34-23.75/4.62-5.07 } \\
\text { Eastern Han } \\
\text { 65.10-68.87/23.01-25.07/4.64-9.12 }\end{array}$ & Not provided & {$[10$, p. 117] } & 2000 & $\begin{array}{l}\text { Mirrors from Ezhou City Museum- } \\
\text { Hubei province }\end{array}$ \\
\hline & $69.73 / 25.23 / 5.04$ & EDS & {$[11$, p. 745$]$} & 2011 & Not provided \\
\hline & $\begin{array}{l}70.88 / 22.27 / 5.59 \\
70.47 / 22.77 / 6.44\end{array}$ & EDS & [12] & 2012 & 2 mirrors-Beijing \\
\hline & $\begin{array}{l}\text { XRF: } 58.40 / 37.2 / 4.2 \\
\text { EDS: } 50.70 / 38.45 / 9.35\end{array}$ & XRF\&EDS & [14] & 2016 & 1 mirror-Hubei province \\
\hline & $\begin{array}{l}\text { Ave. } \\
75.93 / 21.02 / 2.89\end{array}$ & EDS & [15] & 1994 & 14 mirrors-Linxi, Shandong \\
\hline & $\begin{array}{l}.200 / .624 / .270 \\
.157 / .679 / .146 \\
.203 / .615 / .059\end{array}$ & EDS & [27] & 1995 & $\begin{array}{l}3 \text { mirrors } \\
\text { Unknown locations }\end{array}$ \\
\hline & $\begin{array}{l}\text { Eastern Han } \\
\text { Reflective side: } 73.54 / 19.64 / 6.82 \\
\text { Reverse side: } \\
\text { 79.63/13.51/6.88 }\end{array}$ & EDAX & [17] & 2009 & 1 mirror-Guizhou province \\
\hline \multirow[t]{5}{*}{ Song Dynasty } & $\begin{array}{l}\text { Song-Jin } \\
67.88 / 13 / 7.63 \\
67.10 / 8.18 / 23.76\end{array}$ & Not provided & [7,Table 9] & 1961 & $\begin{array}{l}2 \text { mirrors } \\
\text { Unknown locations }\end{array}$ \\
\hline & $\begin{array}{l}\text { Early Song } \\
67.88 / 13 / 7.63 \\
\text { Late Song } \\
67.10 / 8.18 / 23.76\end{array}$ & Not provided & [9. P.114] & 1984 & $\begin{array}{l}2 \text { mirrors- } 1 \text { from Zhejiang province, } \\
2 \text { is unprovenanced; both ana- } \\
\text { lysed by a Japanese scholar }\end{array}$ \\
\hline & $\begin{array}{l}\text { An hui: } \\
\text { 74.59-86.51/6.41-9.99/3.50-18.90 } \\
\text { E cheng: } \\
64.15-74.66 / 6.06-12.66 / 11.83-29.18\end{array}$ & SEM & [29] & 1987 & $\begin{array}{l}4 \text { mirrors-An huin province } \\
11 \text { mirrors-E cheng Hubei province }\end{array}$ \\
\hline & $77.41 / 6.76 / 13.26$ & EDS & [15] & 1994 & 1 mirror-Linxi, Shandong province \\
\hline & $\begin{array}{l}\text { Song/Jin } \\
40.80-84.50 / 4.50-22.2 / 6.1-41\end{array}$ & $\mathrm{pXRF}$ & [16] & 2012 & 10 mirrors-Shanxi province \\
\hline
\end{tabular}


lower melting point than copper and even in ancient times was likely expelled as a gas during the bronze smelting process. It was not smelted in China as a metal until the middle of the 16th century [8]. High levels of zinc $(>10 \%)$ in a mirror indicates a modern reproduction or forgery.

\section{Mirror finishes}

Bronze mirrors were polished after casting to make the surface as smooth as possible to render the best reflective property. Unlike other bronze objects the mirror has a specific and special function so the reflective surface has to be treated to increase the reflective effectiveness. Before the Song dynasty, Xiuwu xun in Huainanzi, 淮 南子-修務訓 [18] mentions that quicksilver was applied to the surface of the mirror and polished in by rubbing with white felt. Quicksilver is a mixture of tin and mercury paste. This process is also called xuan xi 玄錫. Later historic records by Tiangong Kaiwu 天工開物 (Ming dynasty by Song Yingxing) [19] described a similar polishing technique. It was in the Ming dynasty that the combination of mirror manufacturing and associated cultural flourishing led to an accompanying commercial business for maintaining the reflective surfaces of mirrors in a good state.

\section{High tin bronze patina}

Just like other archaeological bronzes, excavated Chinese bronze mirrors present diverse patinas and corrosion morphology. These depend on the drainage and condition of the burial region and patination process as the soil mineralogical constituents and water content have a very significant effect on the bronze over time. The exact constituents of the copper alloy and manufacturing finishes also affect the corrosion process. However, in many cases, bronze mirrors have a tin-rich surface due to the final treatment by the so-called "xuan xi" technique previously described. In these circumstances the mirror surface will be oxidized to varying degrees and react with the underground burial environment and this can form an anti-corrosion layer. This is commonly called qi gu 济 古 and results in a dark black or deep green surface colour and a typically shiny patina. In more modern times there has been much analytical interest in such Chinese mirrors whose surface patina appears very dark or even black as is the case for Mirror 2 in this study in particular. It is generally agreed that the surfaces of these "black" mirrors are no longer metallic but are composed of tin oxides. These result in a 'tin' enriched surface together with significant copper depletion compared to the copper fraction in the main alloy (see later for mirror 3 ).

\section{Methods/experimental}

Aim of the study: To show that valuable diagnostic information, based solely on the physical evidence inherent in potential artifacts, can be retrieved via a careful, objective, multi-facetted, forensic science appraisal with no preconceptions as to the artifact's origin.
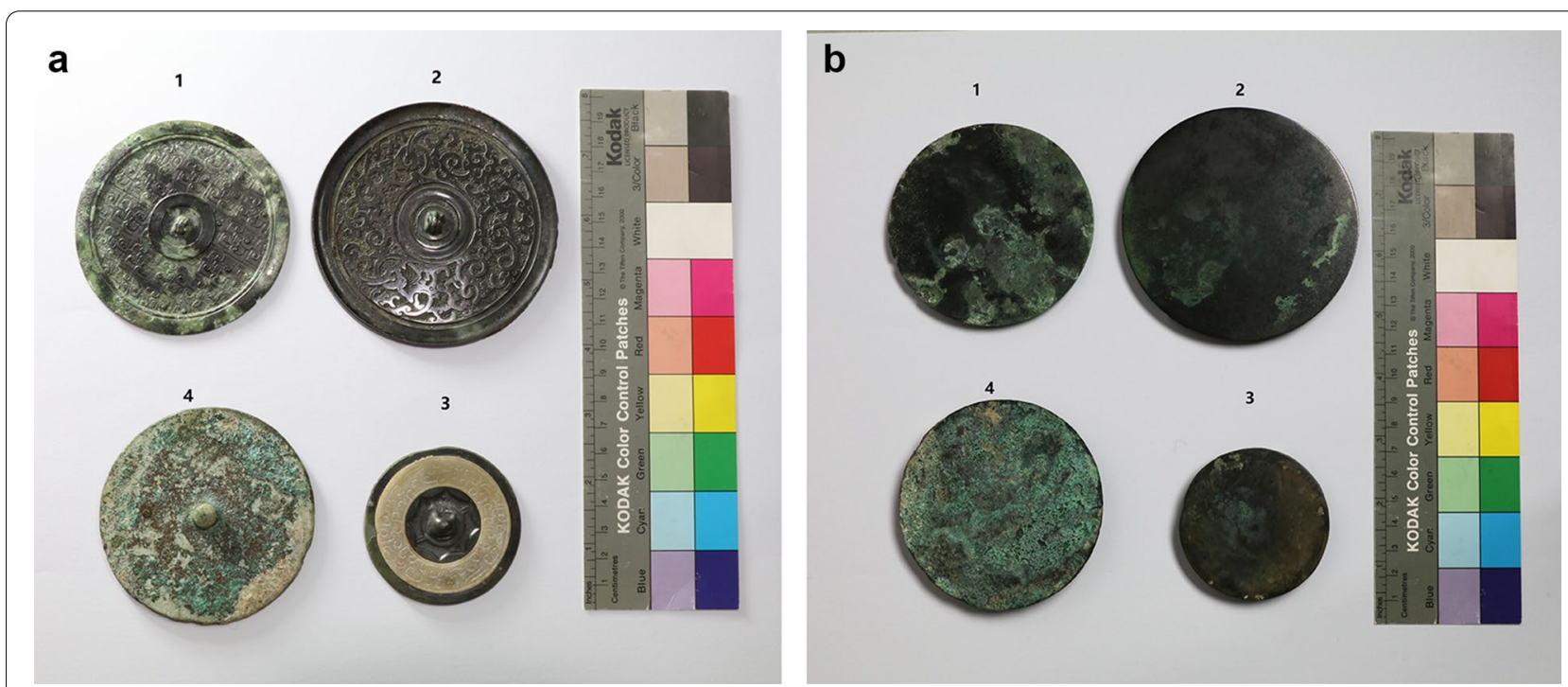

Fig. 1 a The back surfaces of the four mirrors placed alongside each other in the same ambient, natural light with ID number as used throughout and a ruler for the physical scale. $\mathbf{b}$ The front surfaces of the four mirrors 
The Characteristics of the materials: Introduction to the four mirrors of this study

The four mirrors presented together in Fig. 1a and b are all round in shape and each has a central ring-knob that allows the mirror to be suspended on a cord or for a rod to be inserted. Based on the clear style and design elements, mirror 1 , with the feather hook pattern (see later), and mirror 2 with a coiling dragons panchi pattern are nominally dated to the Warring States period (475-221 $\mathrm{BC})$. Mirror 3 is significantly smaller than the others and has a very rare jade, patterned annular ring attached to the back surface and is clearly stylistically dated to the Han dynasty (202 BC-220 AD) with a typical Han sunburst pattern adjacent to the knob. Mirror 4 is the most corroded but is also unadorned and simple without any cast pattern. It is likely a shamanistic mirror and dated to the Song dynasty (960-1279). The iconography and typological design of these four mirrors are fully compatible with the estimated time periods of their potential manufacture.

The basic physical characteristics of these 4 mirrors are given in Table 2 below. The observed variation in thickness is due to the variable corrosion layers across the surfaces.

\section{Processes and methodologies employed: scientific investigations of the four mirrors}

Investigations into the physical characteristics of the 4 mirrors were undertaken using the following instruments and equipment housed within the ACLab, Physics department and Li Ka Shing Faculty of Medicine at the University of Hong Kong, together with application of standard methodologies.

\section{Microscopic examination}

A standard binocular microscope and an Olympus S2X10 binocular microscope with U-TV1X-2 adapter and attached digital camera and a "Nikon Eclipse LV100N Pol" polarized light microscope (PLM) with NIS-Elements and with" D5.00.00" 64-bit software were used to observe and record the microscopic morphology of manufacturing marks, corrosion and archaeological evidence on all four mirrors. An $1000 \times$ endoscope was also used for high magnification imagery.

Table 2 Physical properties of the 4 mirrors

\begin{tabular}{lllll}
\hline Mirror \# & Mirror 1 & Mirror 2 & Mirror 3 & Mirror 4 \\
\hline Nominal Period & Warring States & Warring States & Han & Song \\
Diameter/mm & 85 & 97 & 59 & 84 \\
Weight/gms & 73.98 & 103.1 & 35.0 & 121.0 \\
Thickness/mm & $1.97-2.15$ & 1.56 & $1.99-2.02$ & 3.3 \\
\hline
\end{tabular}

\section{UV examination}

Ultraviolet light, as provided by a Inova X5MT-WUVT lamp with 365-400 $\mathrm{nm}$ wavelength emission, was used to illuminate the mirrors. Any resultant UV fluorescence was noted and can help detect any organic residues, resins or adhesives or modern restoration evident on any of the mirrors.

\section{X-ray fluorescence spectroscopy}

A Bruker ${ }^{\circledR}$ Tracer IV portable X-ray fluorescence spectroscopy (pXRF) was used to provide surface elemental composition via spot testing. On each side of each mirror, no less than 3 spots were tested. Bruker Artex software was used to analyse the resultant data. It is important to appreciate that due to the thickness of the surface corrosions and the low surface penetration of the pXRF, the base alloy composition for each mirror is essentially unknown.

\section{X-ray tomography}

A new to market "MARS" X-ray tomographic spectral scanner was used to provide saggital slices through each mirror (see: https://www.marsbioimaging.com/ overview/). This specific X-ray imaging technology has never been used on bronze artifacts before so we present "world" first results here.

\section{Infrared spectroscopy}

A portable "ASD" high resolution near-infrared spectroradiometer in its $3 \mathrm{~mm}$ fibre-optic coupled contact probe mode was employed to get scattered IR reflectance properties to identify corrossion products.

\section{Chemical solvent spot testing}

Ethanol, acetone and turpentine were all used to perform solubility spot tests on the surfaces of each mirror to check for application/use of resins, adhesives and paints.

Statistical analysis used: The only bulk data requiring any statistical inferences comes from the pXR results for each mirror. Simple standard maximum values are used with a general error estimate only required.

\section{Results}

Results from our experimental and methodological investigation into the physical characteristics and remaining trace evidence of manufacture, treatment, corrosion and archaeology are presented below.

\section{Tool marks}

On mirrors 1, 2 and 3, polishing marks were seen on both sides. On mirror 1 and 2, by using the polarized light microscope (PLM) with reflected light, parallel lines with sharp angles were observed. This type of line is likely 


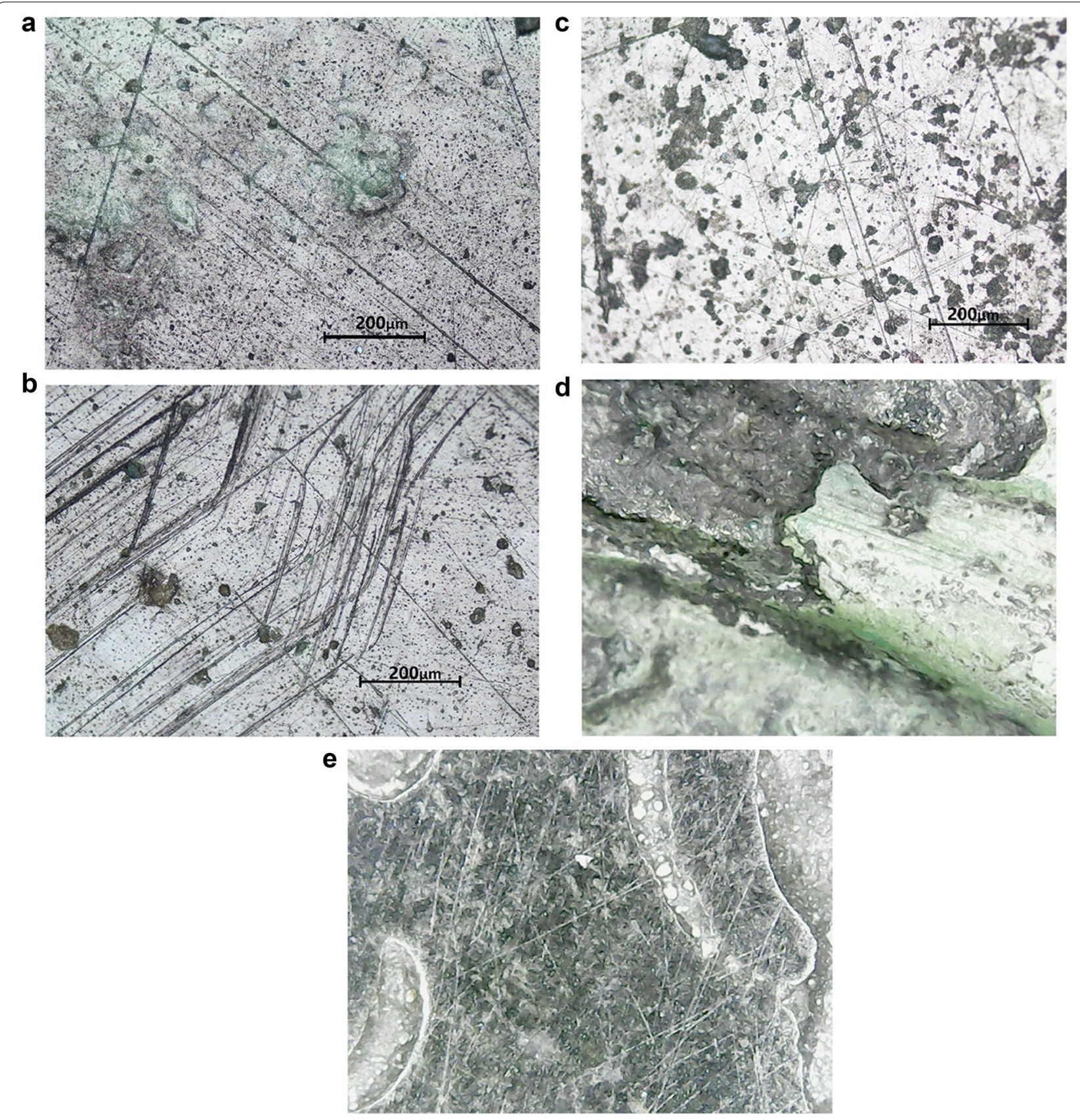

Fig. 2 a Surface tool marks (scratches) on Mirror 1. It can be seen that these marks go across the protruding corrosion on the mirror surface and are not beneath this corrosion. This indicates later abrasive cleaning of the reflective surface of this mirror after some corrosion products have formed. b Polishing lines (scratches) on the reflective surface of Mirror 2. Some of these have sudden sharp angled changes in polishing lines likely due to some mechanical polishing process. Here some corrosion sits on top of some of these marks indicating an older polishing process before some of the corrosion products have formed. $\mathbf{c}$ Polishing lines on the reflective surface of Mirror 3. There are a mixture of fine and broad parallel streaks indicating different cleaning abrasives and likely different periods of cleaning. There are a larger number of surface defects per unit area compared to mirrors 1 \& 2. d A $\times 40$ image of a region of top-level thick ( 200 micron) green patina on the back surface of mirror 1 . Evidence of strong abrasive cleaning is seen as parallel score marks on this green patina. The more corrugated surface of the metal alloy underneath where this thick patina has become detached is also clear. e A $\times 40$ image of part of the shiny, black patina on the back surface of mirror 2 taken on one of the spiral patterns. Again, very clear evidence of strong abrasive cleaning is seen as a series of fine criss-crossing linear score marks. The fine shine on this side likely indicates recent abrasive cleaning 
caused by mechanical polishing of the surface [34]. For mirror 1 the marks can be seen on-top of some protruding corrosion rather than passing beneath them (Fig. 2a and $\mathrm{d}$ ). This indicates that this polishing was done post formation of these corrosion and that an aggressive cleaning of the surface was undertaken quite recently, perhaps to remove significant corrosion to get to the base metal surface in attempts to improve the mirror "aesthetics". For mirror 2 it is clear that newer corrosion components have formed on top of some of the presumably older tool marks (see arrowed examples in the figure) while the surface has some inclusions that are many times $(10 \times)$ larger than those small surface defects seen on mirror 1 (Fig. $2 \mathrm{~b}$ and e). Mirror 3 is similar to mirror 2 but has a factor of $3-5 \times$ more surface defects with a mixture of broader and finer tool marks. In some cases the cleaning tracks can be seen going through these surface defects. In another case (top left of Fig. 2c) these tracks are under the corrosion. These tracks also have a broader spread of angles across the surface indicating several different cleaning episodes. Due to the highly corroded surface, there are no polishing marks that can be observed on mirror 4.

\section{Patina}

Mirrors 1 and 2 have a black, shiny patina on their fronts (see Fig. 1b) common to mirrors from the Warring States period. The areas without pitted corrosion still present a reasonably reflective surface. Mirror 3 has as a variable, very dark to lighter green patina. From a region towards the edge of mirror 3 where the overlaying shiny patina has become detached, the division of surface patina and further corroded metal underneath is distinctive. In this small area, where the lighter shiny olive green patina has come away, a lower level "crinkly" sub-surface is evident Fig. 3(left). This is seen in many other bronzes from
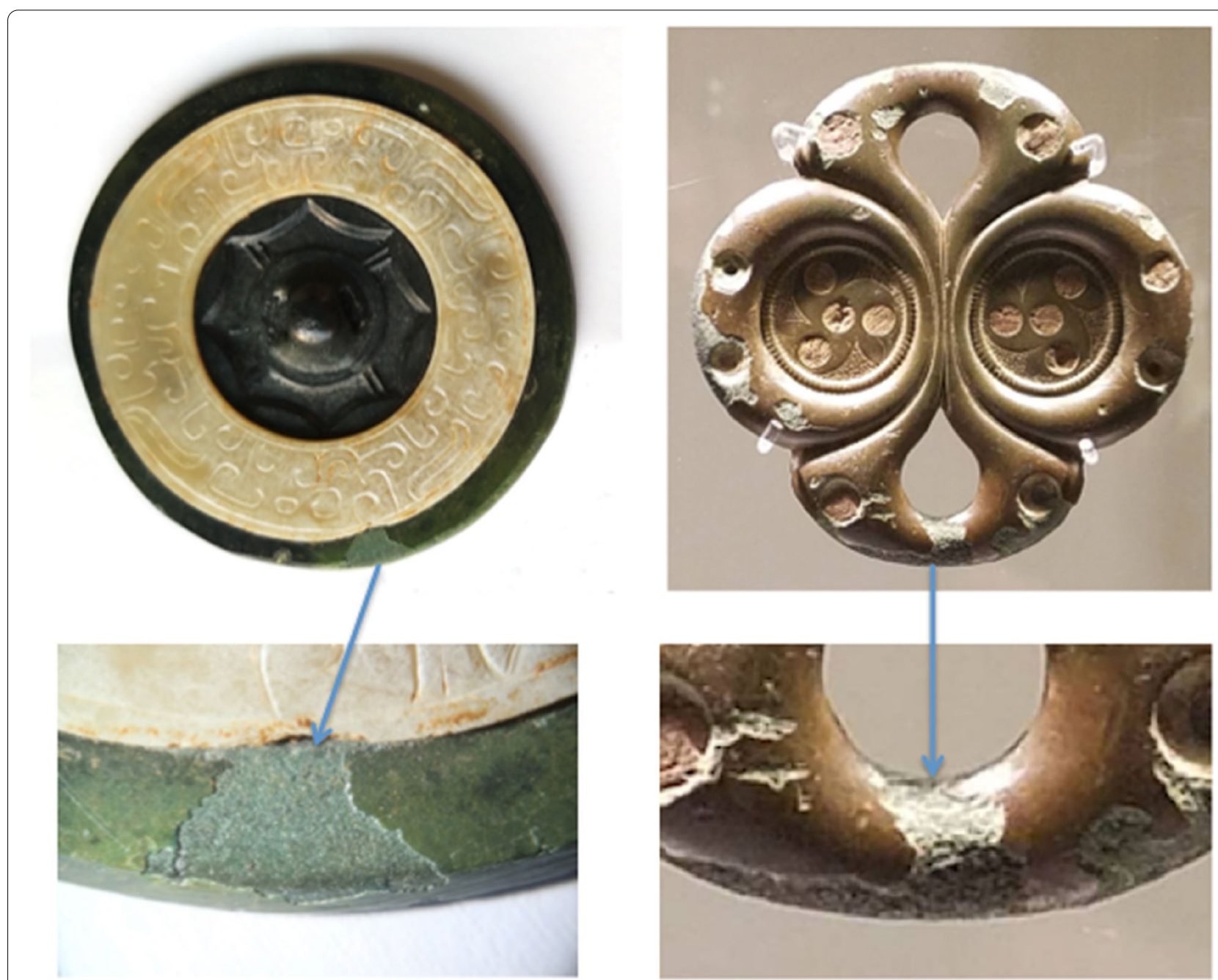

Fig. 3 Montage of the Han mirror 3 (left) and 2nd century AD roman brooch (right) with inserts highlighting the common patination feature 
antiquity. An example is shown in Fig. 3 (right) of a 2nd century AD Roman brooch from Cirencester museum in the UK (photo taken by the 2nd author in situ in December 2017). This is shown next to mirror 3 together with arrowed inserts showing the common patination features. Both mirror and brooch are from approximately the same time period, both are small in size and have similar light to dark olive green shiny patinas. However, in both examples the top level patina has flaked off in some places to reveal a crinkly, sub-surface condition. Such features are, to our knowledge, not present in modern replicas.

\section{Archaeological evidence}

Mirror 1 does not have any obvious archaeological evidence such as any encrusted earth deposits or any other phenomenon related to a burial history such as attached organic material, including textile pseudomorph marks from wrapping in cloth prior to burial. Mirror 2 does have some apparent encrustation remaining on the mirrors' $3 \mathrm{~mm}$ wide edge that extends for about $2 \mathrm{~cm}$. Images of this attached encrustation are shown in Fig. 4a at $40 \times$ magnification. A fine implement can remove this material quite easily. Both mirrors 1 and 2 appear to have been heavily cleaned (see Fig. 2a, b). For mirror 3, within

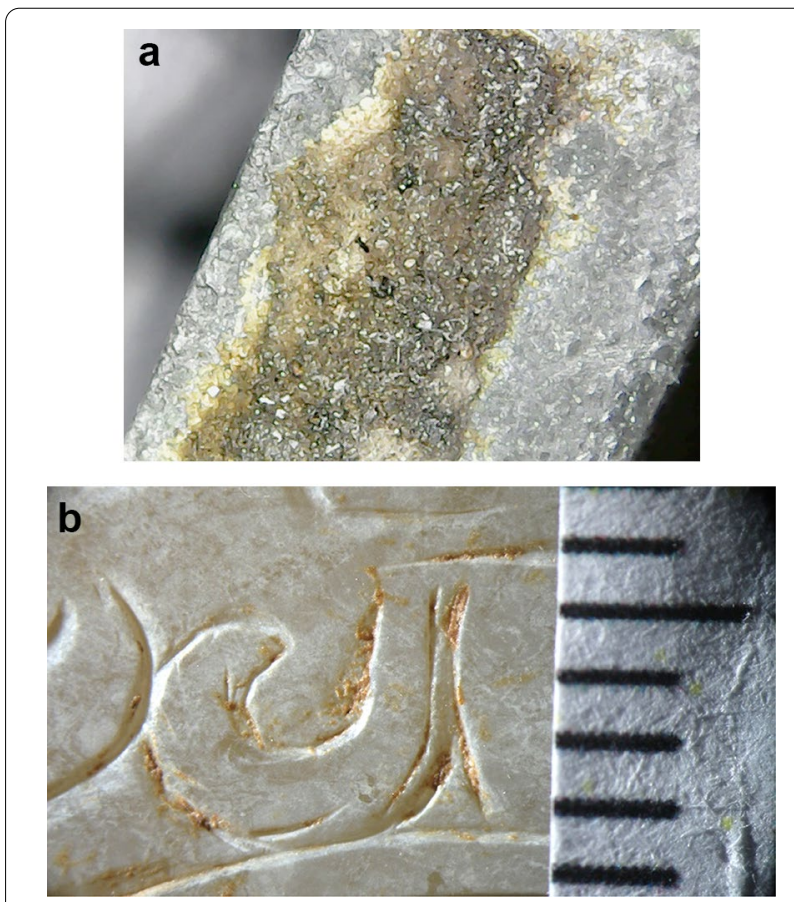

Fig. 4 a $A \times 40$ image of residual encrustation on the edge of mirror 2. The feature extends for $\sim 2 \mathrm{~cm}$ along the edge of the mirror and has a dark brown-grey color but lighter at the exposed edges. $\mathbf{b}$ Earthen crust deposit in the incisions made on the jade ring annulus attached to the back of Mirror 3. The scale to the right is in $\mathrm{mm}$ the incisions of the inscribed pattern of the jade annular attachment, some traces of earthen encrustations were also observed. By touching by scalpel, these encrustations are very hard to remove. The formation of this type of crust on a jade surface is usually caused by a prolonged burial history. The jade annulus itself is $12 \mathrm{~mm}$ wide with an outer diameter of $52 \mathrm{~mm}$ and inner diameter of $28 \mathrm{~mm}$ with a typical late-Warring States simple, scrolltype, panchi pattern. From microscopic examination, it is clear this piece was not worked with modern machine tools but betrays the tell-tale marks and scratches typical for jade hand-worked from this period and evident in Fig. 4b. The jade annulus itself is at least partially recessed into the bronze mirror being almost flush with the surface on one side with a protruding thickness of $\sim 1.9 \mathrm{~mm}$ for the most part but closer to $3 \mathrm{~mm}$ for the inner edge closer to the central boss.

On mirror 4, the overall surfaces are quite heavily corroded and covered with deep greenish blue corrosions raised from the base mirror surface together with some white crust along one edge. Textile pseudomorph marks were observed on this particular corrosion layer (see
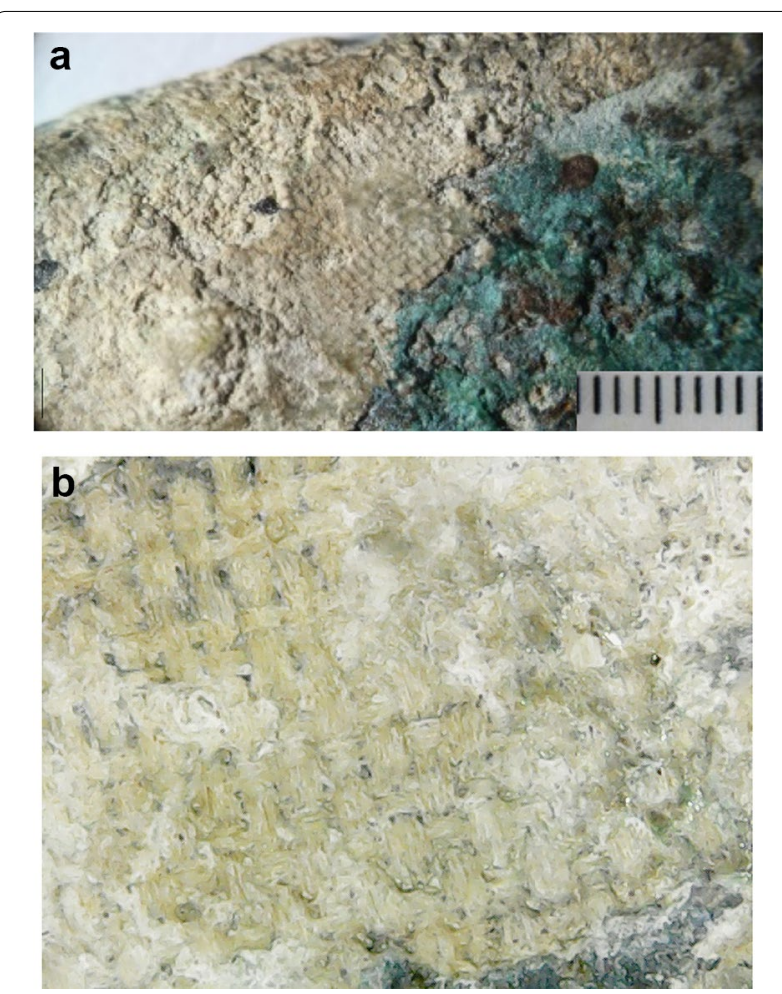

Fig. 5 a White region of mirror 4 back surface showing textile pseudomorph impressions left by a linen type fabric used to wrap the object during burial. The pich between warp and weft is $\sim 0.5 \mathrm{~mm}$. The scale to the right is in $\mathrm{mm}$. $\mathbf{b} \mathrm{A} \times 40$ close up of textile pseudomorph for mirror 4-the character of the decayed woven material is beautifully preserved 


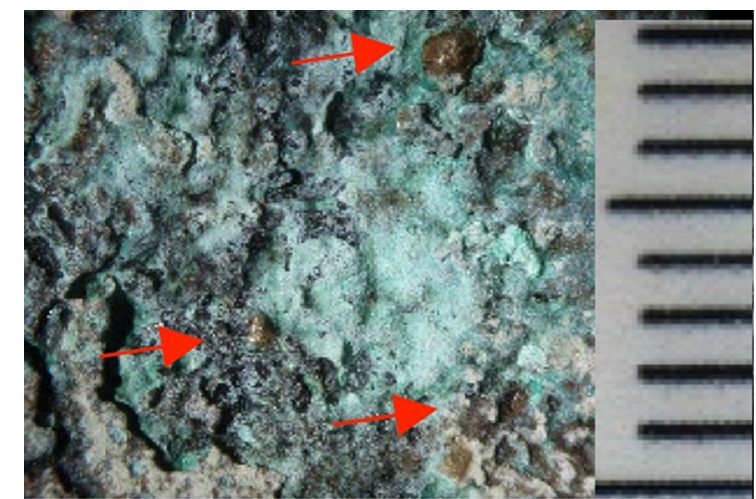

Fig. 6 Several insect husks $\sim 1 \mathrm{~mm}$ in size embedded into the heavy corrosion on the back surface of mirror 4 . The scale to the right is in $\mathrm{mm}$

Fig. 5a, b). This area also fluoresces bright yellow under UV light indicating some non metallic possibly organic material is present in this region (see Fig. 13). The impressed textile marks look natural. From the woven pattern (Fig. 5b), it is likely from a linin fabric. It is not rare to see such textile pseudomorph marks on bronze mirrors and other bronzes. As an important and elegant personal belonging, mirrors were usually buried with the owner, and sometimes wrapped with a textile [15, Fig. 10]. After a long time underground, the textile, which is an organic material, deteriorates away. Each textile fibre has been replaced by mineral salts preserving the pattern but the actual organic component has gone. This is true especially in the regions where underground water levels fluctuate actively. Several insect carcasses can also be seen embedded in the thick corrosion and some charcoal (see Figs. 6 and 12).

\section{Corrosion morphology}

The surfaces of mirror 1 have been well preserved but extensive abrasive cleaning seems also to have been undertaken perhaps in the recent past. On the front surface, towards the mirror edges severe pitted corrosion can be seen in several places that has eaten into the smooth, light green surface patina. By looking at these areas where the surface patina has been broken-up, 3 distinct layers can be distinguished (see Figs. 7 and 8). The top layer is a light green, 200 micron thick shiny patina, underneath is a black layer and under this is a layer of greenish powdery, pitted depressions. It is hard to tell if the corrosion starts from inside the metal or has ingressed from outside. We believe the black middle layer is the original mirror surface akin to what is seen for the other "warring states" mirror 2 and resulting from application of the "xuan xi" technique referred to earlier.

However, given the absence of metal surface where the pits are exposed and the trend of the increasing density of

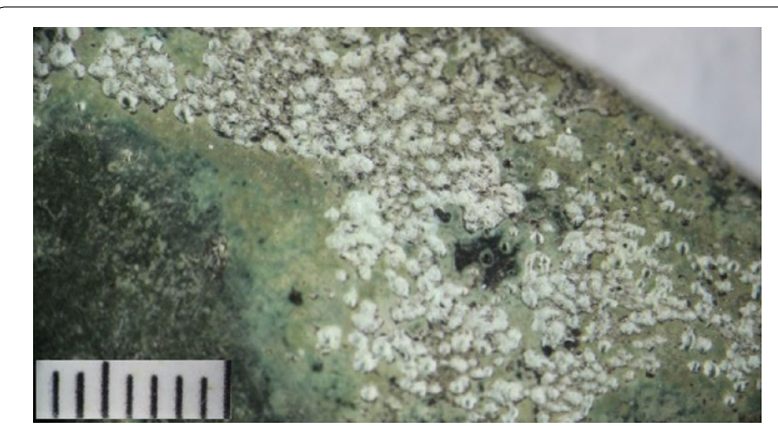

Fig. 7 Region at the edge of the back surface of mirror 1 showing the top layer (shiny green patina), middle black layer and pitted, powdery corrosion underneath. The scale to the left is in $\mathrm{mm}$

number of pits around the powdery area, it is very likely that the corrosion starts from each single pit where moisture has gotten into the metal to stimulate the process of decuprification to form green corrosion and then turn into powdered corrosion. In certain regions the original metal surface is gradually replaced by this green corrosion. Along with forming increasing green powder corrosion, the green surface has been eaten away. Therefore, the green surface is the middle phase of the whole deterioration process. On the back surface, towards the mirror edges, the thick green layer is absent where a black rough metal underneath is exposed (Fig. 8).

For mirror 2 both front and back surfaces are well preserved with the surfaces dark, almost black in colour. A similar corrosion phenomenon (Fig. 9) to mirror 1 can also be seen on parts of the front surface of mirror 2 although in this case there is no additional green surface patina on top of the dark layer. It is possible this has been removed by aggressive cleaning. Both mirrors one and two were acquired at the same time from the same vendor. On the back surface towards the edge in one area in particular, a rougher surface is observed. It was likely

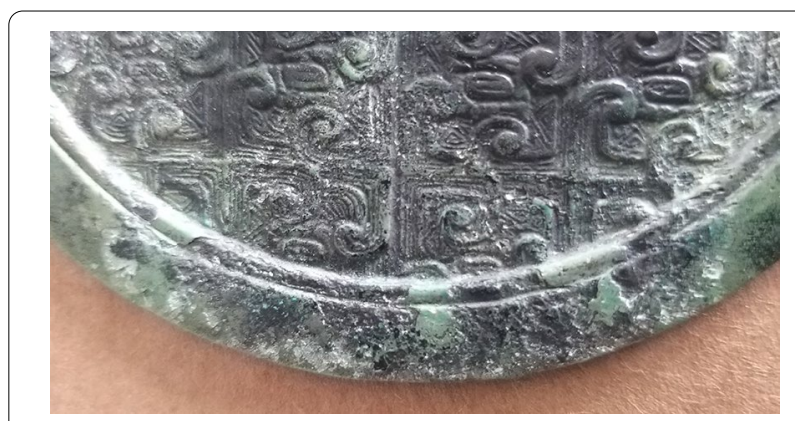

Fig. 8 Reverse surface of mirror 1 showing regions of the top smooth, thick, green patina that is largely flaked off to reveal the black, metal layer underneath, there is little pitted corrosion in this region 


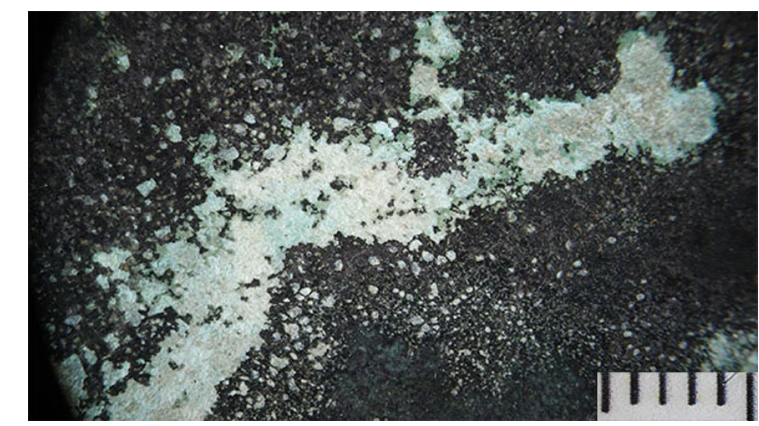

Fig. 9 Pitted corrosion on the front surface of mirror 2. The scale to the right is in $\mathrm{mm}$

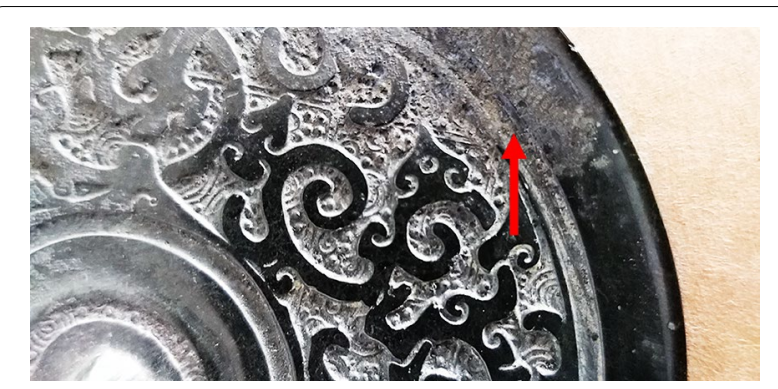

Fig. 10 Close up of the coiled dragon pattern on the back surface on Mirror 2 showing an area of dark surface encrustation towards the edge. The pattern definition looks sharp and clean until this point

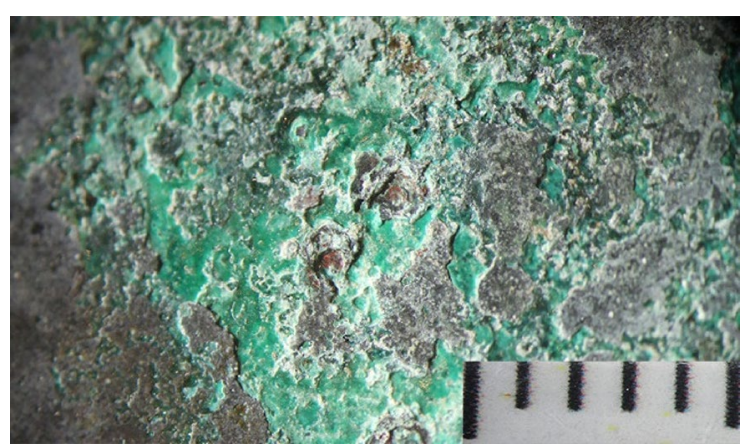

Fig. 11 Green malachite and red cuprite corrosion near the centre of mirror's 3 reflective surface. Similarly identified corrosion can be seen in Fig. 228 \& 240 of Ref. [32]

formed during the manufacturing process since part of the relief is disturbed (Fig. 10).

For mirror 3 the front surface is mainly smooth and dark. However, there are regions of bright green malachite corrosion along with small regions of red corrosion which is assumed to be cuprite, as shown in Fig. 11. On the front surface there is also a meandering hairline crack within the body of the mirror (refer Fig. 14) that does not

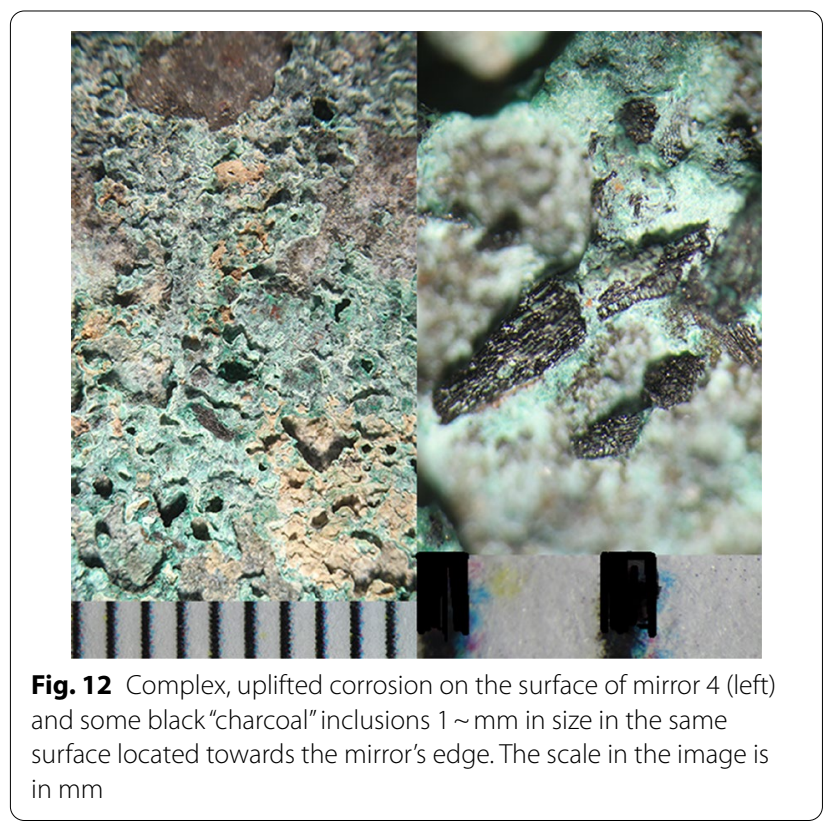

extend to the edges. It has an overall extent of $\sim 5 \mathrm{~cm}$. Mirror 4 is covered with thick green corrosion. In some regions, small, black "charcoal" like inclusions can be seen within the corrosion (Fig. 12 right).

Small samples of the greenish white powdery corrosion from the pitted areas on mirrors 1 and 2; the green and red corrosion from mirror 3; and the white encrustation, green corrosion and black inclusions from mirror 4 were taken. These samples were mounted with Meltmound ${ }^{\circledR}$ 1.662 resin on glass slides for PLM. The result are given in Table 3.

On mirror 1 and 2, the greenish white powdery corrosions were identified to be copper hydroxide (spertinite). Copper hydroxide is regarded as an unstable and an intermediate product that will transform to a more stable mineral such as copper carbonate during the corrosion process [23, p. 98]. There is no indication as to when and how this deterioration process started on mirror $1 \& 2$, especially with traces of the modern intervention found.

On mirror 3, the green corrosion on the reflective surface is confirmed to be malachite by PLM and confirmed by infrared spectroscopy (see later). Due to the limited sample obtained from the red in round-shape corroded area (Fig. 11), only one particle was successfully mounted on a glass slide. The particle looks quite dark in both plane and cross-polarized light. PLM did not offer strong diagnostic information to this red corrosion. However, from the formation shape and colour, it is very likely cuprite [32], Fig. 240]. Scott [23, p. 106] indicated that a natural transaction from cuprite to malachite is very hard to duplicate in the laboratory. In other words, the 
Table 3 PLM results of corrosion products from mirrors 1-4

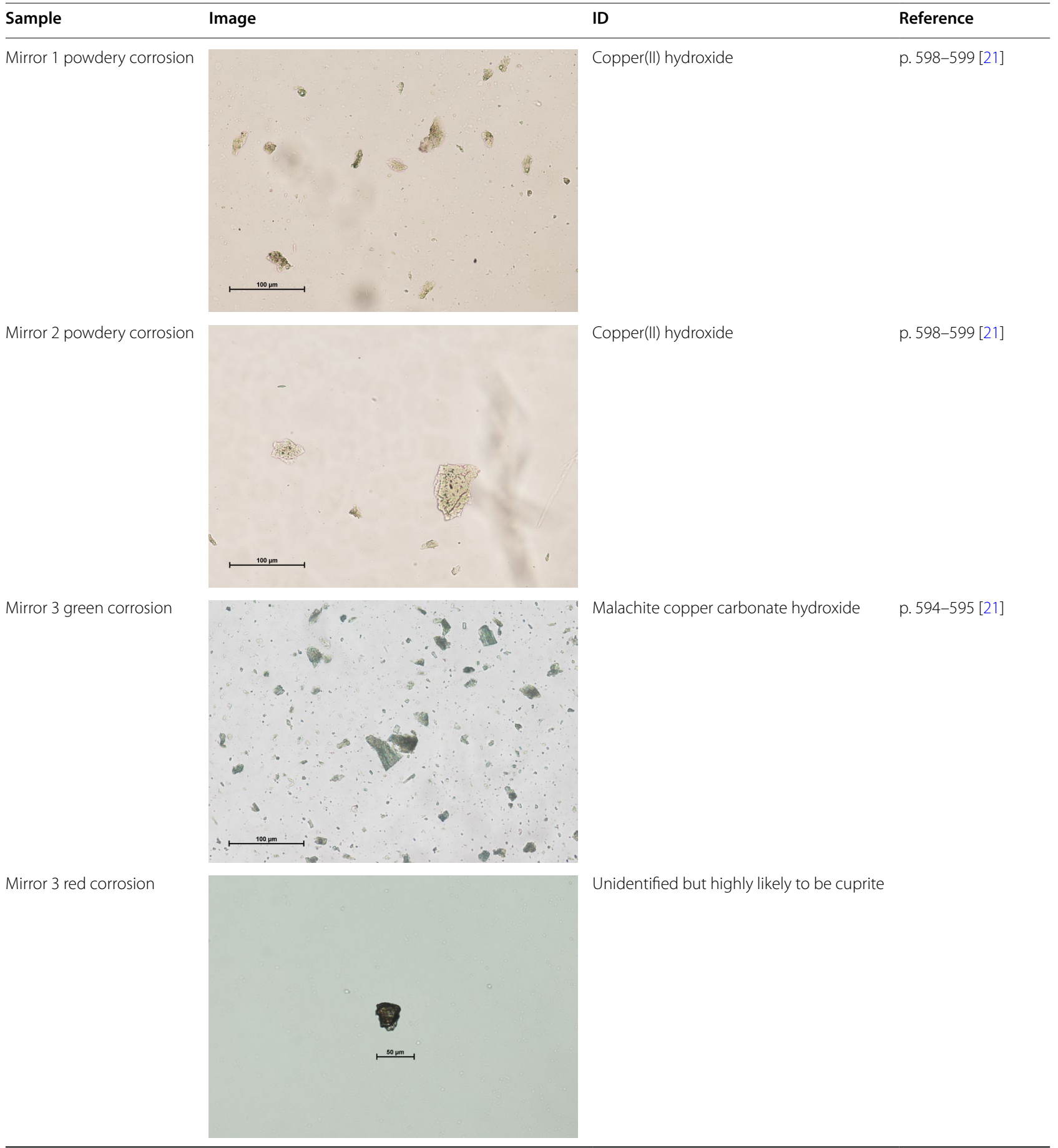


Table 3 (continued)

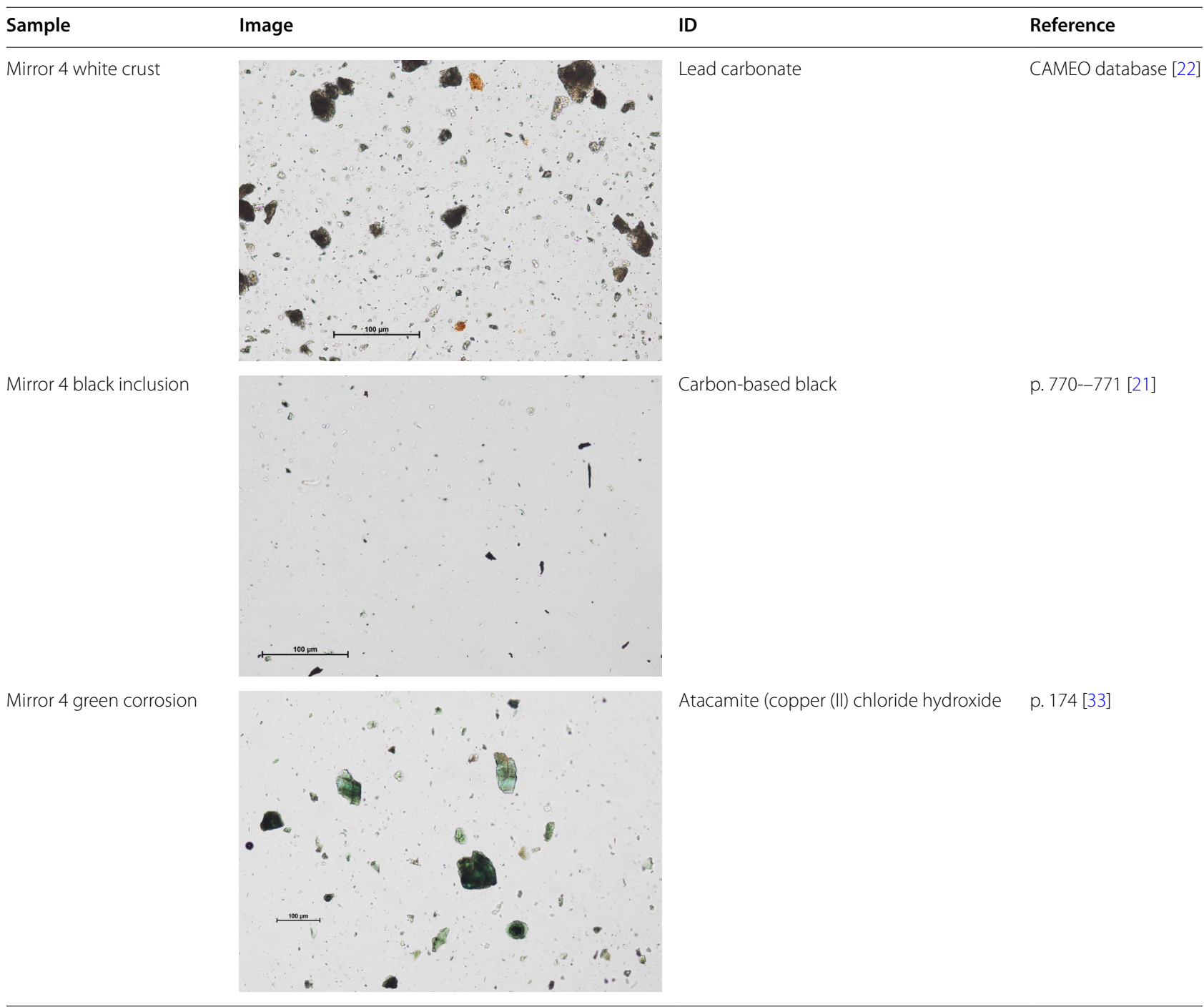

presence of cuprite covered with malachite, as seems the case here, is strong proof of the truth that the formation of malachite is natural on this mirror.

For mirror 4, the known process of the migration of lead within the alloy affects the composition of the distinct but localised white crust that bears the textile marks (pseuodomorphs). The pXRF result on this area (see later) shows that the whitish crust on mirror 4 has a very high lead value (up to 93\%). When the content of lead exceeds tin in a bronze it would form thick and crusty corrosion products mostly of carbonates and oxides of lead [32]. PLM proves the white mineral is lead white (lead carbonate). The black inclusion is confirmed to be carbon based black. The bond of this top black inclusion and the green corrosion underneath is strong which does not allow easy sampling. This indicates the carbon black existed on the surface along with the growth of the copper corrosion. The green corrosion on mirror 4 was identified to be atacamite.

\section{UV fluorescence imaging}

UV fluorescence imaging has been a valuable diagnostic tool in the art and archaeology fields since the 1920s [24]. The four mirrors were subjected to UV illumination to detect if any modern restorations or applications (e.g. using adhesive/paint to attach a false surface patina), have been done. The results show that no restorations have been found on any of these mirrors. Mirror 3 had evidence for a brown "glue" under the jade annulus that is fixing it onto the back surface of the mirror. UV imagery did not reveal any fluorescence indicating that whatever was used to fix the jade annulus in place was not any modern resin or adhesive. Furthermore, the strongly attached encrustations here and there within 
the jade carvings did not fluoresce either so these are not modern "glued-on" material that is sometimes used to create an impression of authenticity by the unscrupulous. UV imagery of Mirror 4 did reveal in stark relief the grey-white areas of corrosion associated with the textile pseudomorph regions. This indicates that some organic components may remain in the fluorescent region (Fig. 13).

\section{Surface metallurgy from pXRF measurements}

For each mirror, 3-4 test spots were chosen for analysis using pXRF. Here it is crucial to appreciate that the pXRF measurements only penetrate a small distance into the surface. Hence, where the corrosion is thick, only these products can be assessed. All data was therefore from the surface but the cleanest regions where chosen wherever possible. For mirror 4, the data was collected from the area with the least green corrosion. The "vacuum" attachment and lower $\mathrm{kV}$ and high current was used for the corroded area in order to detect chloride and lighter elements. Bruker ${ }^{\circledR}$ Artax analytical software was used to analyse the data. By analysing the net count rates, which are the number of photons recorded for each element after removing other elemental interference and background, a percentage by abundance for each recognized element was calculated. Given the data was taken from the surface layers, where any corrosion or residues would affect the absolute value, the averaged results from the combined 4 spot measurements should be regarded as quantitative of the mirror surfaces only.
The pXRF data was taken at $40 \mathrm{kV}, 20 \mu \mathrm{mA}$, with the yellow filter for metal analysis with $120 \mathrm{~s}$ exposures for each spot. Table S1 results in Additional file 1 are the averages from the 3-4 spot measurements. The K12, L1 and M1 designations refer to electron shells where $K$ denotes the first shell (or energy level), L the second shell and $M$, the third shell.

From the pXRF analysis of the alloy composition of the four mirrors they are all bronze, i.e. a copper-tin-lead ternary alloy with variation of minor and trace constituents. Those additional trace elements apparent in the mirrors are also seen in other ancient Chinese bronze artifacts. Iron, silver, gold, nickel, cobalt, zinc, bismuth and antimony are regarded as impurities from the unrefined base ores accessed in antiquity [32]. Manganese, barium, calcium are from the earth encrustation or contamination on the surface of the mirrors. Silicon was not detected because the pXRF measurement parameters are set for metals. Zinc is not over $10 \%$ in any of these mirrors which indicates that none are poorly made, easily acquired modern fakes where high levels of zinc are common $[25,26]$.

As seen in Table 1 the observed fraction of copper in provenanced Chinese bronze mirrors is quite wide, ranging typically from 65 to $80 \%$. In the case of a heavily corroded surface or a surface of qigu, the copper content can be quite low. Hence copper content is not a top diagnostic factor in bronze mirror appraisal based on elemental composition. He [15, p. 76] states that mirrors dated to the Warring States typically have a tin fraction that is

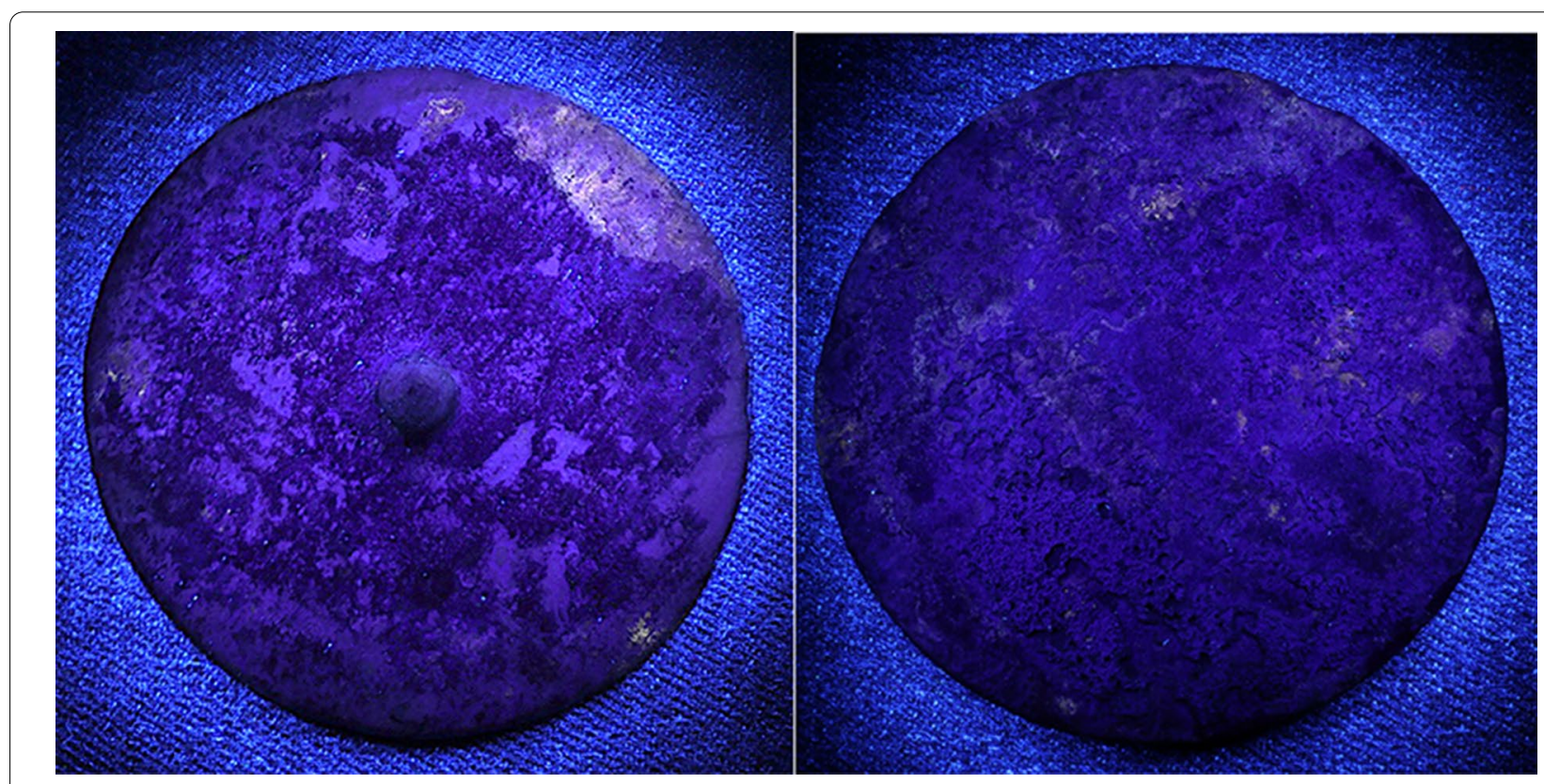

Fig. 13 UV imagery of back and front surface of Mirror 4. The lighter areas correspond mainly to the textile pseudomorph impressions 
much higher than lead. The range in the amounts of tin and lead found in mirrors 1 and 2 does not match the opinion of He. Here it is only $17-24 \%$ tin c.f. $8-20 \%$ lead. He and Song [15] also indicated that mirrors dated to the Warring States with low fraction of iron $(\mathrm{Fe})$ were probably unearthed from central China Shaanxi, Shanxi province or from inner Mongolia. For mirror 2 in particular, the observed $20.2 \%$ lead is much higher than the current reference record.

For mirror 3 the surface copper content is extremely low while the tin content is $50 \%$. The likely formation of green qigu (Fig. 3) contributes to this outcome. Similar data on $\mathrm{Cu}$-Sn ratios were achieved on mirror surfaces by $\mathrm{He}$ [36] and given in a scientific report [28] by the lab in University of Science and Technology of China in 1988. Although 50\% tin was achieved from surface measurements, the presence of a crack indicates the brittleness of the alloy in this mirror (Fig. 14). Indeed, the drawback of high tin content is that it can lead to a brittle copper alloy. Most published data on the lead content on the surface of mirrors dated to the Han dynasty are less than $10 \%$. Therefore, the lead in mirror 3 is in the reasonable range for provenanced Han bronze mirrors.

For mirror 4, due to the highly corroded surface, the ratio of major elements found should not be considered as representative of the metal surface. Even so, the ratios of each element fall into the range of published data on archaeological provenanced mirrors dated to the same period. According to He and Song [15], a Song mirror unearthed from Linxi, Shandong province (northern China) present a high lead content (35.11-35.75\%) on its surfaces. Conversely, mirrors unearthed from Echeng City in Hubei province (southern China) show a relatively low lead component (average $20.220 \%$ for 12 mirrors) [29]. An interesting phenomenon for mirror 4 is

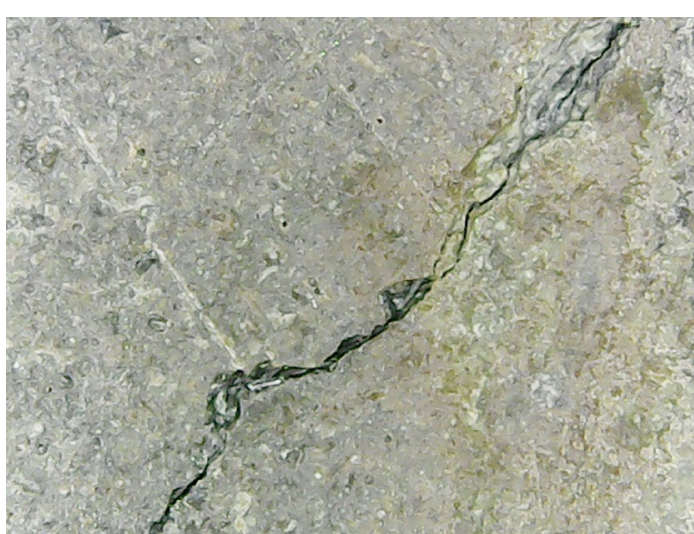

Fig. $14 \times 40$ Magnified region of the crack on the reflective surface of Mirror 3 the much more highly corroded surface compared to the other three mirrors and that the measured lead fraction is high, averaging $\sim 38 \%$ on the front surface. There are two possible explanations and sources for the lead. (1) It is migration to the surface from within the alloy itself; (2) It arises from the lead mercury finishing paste used to keep the reflective surface shiny [20]. This could at least also partially explain why the front surfaces for mirrors 2,3 and 4 also have a higher lead content. No matter what the source is, lead is an active factor in causing more corrosion. This is also true for other types of bona-fide archaeologically excavated bronzes with high lead content [30].

\section{pXRF and the presence of mercury $(\mathrm{Hg})$}

Trace but reliable levels of mercury $(\mathrm{Hg})$ were detected on both mirrors $3 \& 4$, indicating that these two mirrors at least were likely treated with the quicksilver polishing technique described in the historical records. No mercury was detected on mirrors 1 and 2 . It is hard to conclude that no mercury was used to treat these mirrors since if heat was involved during the process, the mercury may evaporate [25].

\section{pXRF and the presence of chromium ( $\mathrm{Cr}$ )}

There is chromium $(\mathrm{Cr})$ present on both mirrors 1 and 2 as a trace element. A few ancient bronzes have been discovered bearing chromium that have been studied in the past 30 years. Scholars are interested in whether such chromium was added deliberately by the ancients for anti-rust purposes. However, most investigations [38-40] pointed out that the chromium was not an intentional addition but a contamination from the natural environment, except perhaps for one bronze Pan dated to the Warring States Chu Culture [37]. The content of chromium in the sample surface-film by Luo [37] for this bronze Pan is $35.61 \%$, much higher than the average content in any other publication and much higher than found here for mirrors 1 and 2 (less than $1 \%$ chromium). As chromium (III) oxide $\left(\mathrm{Cr}_{2} \mathrm{O}_{3}\right)$ is a modern polishing product used on metal we conclude that the detected chromium is more likely a result of cleaning with chromium oxide more recently, especially considering the sharp angled modern polishing tool marks observed on the reflective surfaces on mirrors 1 and 2. Interestingly, these two mirrors came from the same source. This may also explain the absence or very low levels of mercury on those two mirrors, where a heavy, abrasive polish could have removed any remaining trace of mercury.

\section{pXRF of the corroded areas}

The pXRF with settings of $15 \mathrm{keV}, 36 \mu \mathrm{mA}$, vacuum implemented and with $120 \mathrm{~s}$ exposure testing times were used to analyse chosen corroded areas on pitted areas of 
mirror 1 and 2 to detect chloride $(\mathrm{Cl})$ which commonly causes 'bronze disease', seen as greenish white powder on bronzes [26]. However, no chloride was detected. For mirror 3, data was collected on the green corrosion on the reflective surface as in Fig. 11. The green corrosion and thick crust on mirror 4 were also analysed. Figure 15 shows the elemental distribution on the targeted areas on the four mirrors.

Figure 15 shows the elemental variation on the corroded area of these four mirrors. The pitted areas on mirror 1 and 2 are found to be mainly copper and tin compounds, no chloride was detected. Chromium is only present on mirrors 1 and 2. Lead dominates the corrosion crust on mirror 4 .

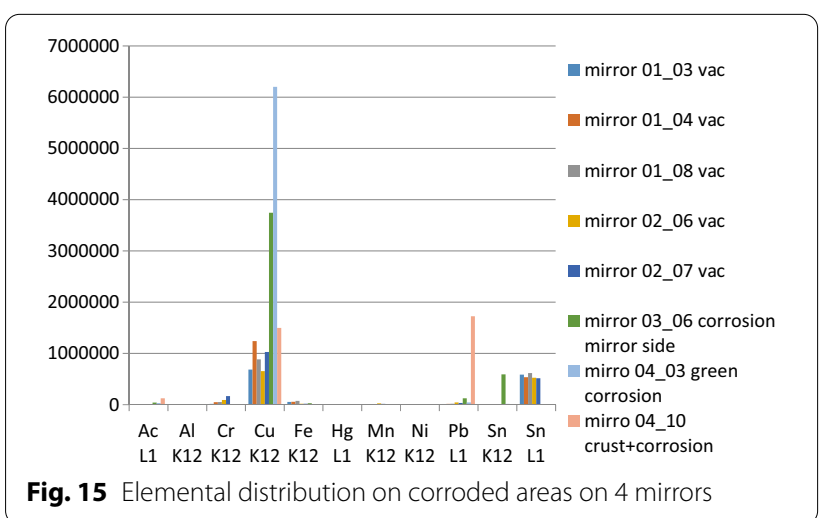

\section{X-ray tomography}

A MARS tomographic 3-D X-ray spectral scanner was used to produce saggital X-ray scans of these 4 mirrors. This is new technology designed for bio-imaging applications that generates multi-energy images with high spatial resolution and low noise. The use of this scanner for bronze artifacts is a world first that required extensive testing and characterisation before useful data could be obtained for these mirrors. The best scanning characteristics established through trial and error are given in Table 4.

The most interesting X-ray results comes for the Han mirror 3 which shows that the metal surface under the jade annulus (not registered in these higher energy X-ray images) is flat and unadorned as shown in Fig. 16a. Most Han mirrors have a pattern here but the lack of one indicates the high likelihood that the mirror was made for the jade annulus (which may itself date from the Warring States) rather than being added later. The hole through the central knob is also shown to be non-tangential. As saggital scans delve deeper into the mirror irregularities in the bronze smelt are also evident (Fig. 16b) giving further credence to imperfections in the smelting and alloy mixing process. This process is much more homogeneous in modern replicas (Fig. 17).

For mirror 2 no irregularities in the saggital slices through the mirror were seen implying a much more homogeneous alloy mix-so no imagery is presented.

Due to its thickness mirror 4 was very difficult to scan properly with MARS but from what was possible it is clear there are significant variations in the internal alloy density distribution and structure as shown in the two examples below for the same mirror segment (Fig. 18).

Table 4 MARS best-estimate scanning characteristics determined for these mirrors

\begin{tabular}{|c|c|c|c|c|c|c|c|c|c|c|}
\hline Mirror & ASN\# & $\begin{array}{l}\text { FOV } \\
(\mathrm{mm})\end{array}$ & $\begin{array}{c}\text { Tube } \\
\text { voltage } \\
\text { (kVp) }\end{array}$ & $\begin{array}{l}\text { Tube } \\
\text { current } \\
\text { (uA) }\end{array}$ & $\begin{array}{l}\text { Exposure } \\
\text { time } \\
\text { (ms) }\end{array}$ & Filter & $\begin{array}{l}\text { SOD } \\
(\mathrm{mm})\end{array}$ & $\begin{array}{l}\text { ODD } \\
(\mathrm{mm})\end{array}$ & $\begin{array}{c}\text { Energy } \\
\text { thresholds } \\
(\mathrm{keV})\end{array}$ & $\begin{array}{l}\text { Voxel } \\
\text { size } \\
(\mathrm{mm})\end{array}$ \\
\hline $\begin{array}{l}1 \\
\text { (Han) }\end{array}$ & $475 F$ & 80 & \multirow{4}{*}{120} & \multirow{4}{*}{330} & \multirow{4}{*}{250} & \multirow{4}{*}{$\begin{array}{l}7 \mathrm{~mm} \\
\text { copper }\end{array}$} & \multirow{4}{*}{210} & 60 & \multirow{4}{*}{$\begin{array}{l}70,80,90, \\
100\end{array}$} & \multirow{4}{*}{0.09} \\
\hline $\begin{array}{l}2 \\
\text { (corroded) }\end{array}$ & $477 F$ & 110 & & & & & & 64 & & \\
\hline 3 & $476 F$ & 110 & & & & & & 64 & & \\
\hline 4 (WH) & $474 F$ & 118 & & & & & & 64 & & \\
\hline
\end{tabular}

The ASN\# is just the identification number for a given scan run. FOV stand for field of view (or sample diameter), SOD is the source-to-object distance, and ODD is the object-to-detector distance. As these are 3-D tomorgraphic scans there is a volumetric pixel or "voxel" which here was set at a resolution of 0.09 mm. To reduce artifacts in the scans a $7 \mathrm{~mm}$ copper filter was inserted between the artifact and the X-ray beam in conjunction with long exposure times and high beam currents to maximise transmitted X-ray photons through each mirror 


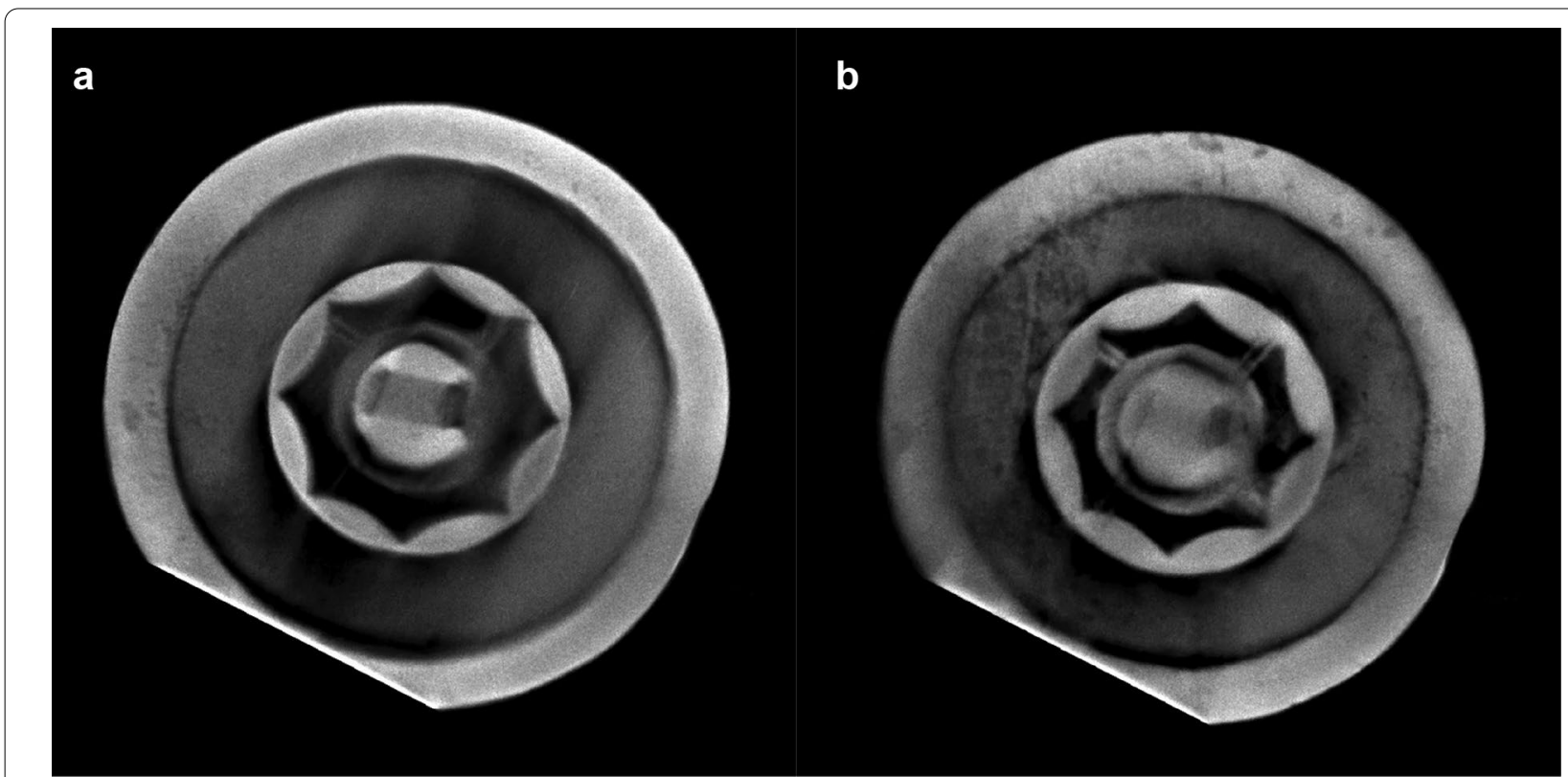

Fig. 16 a Left: Saggital X-ray scan of top reverse side of the surface of mirror 3. This shows the clean unpatterned metal surface under the attached jade annulus and the alignment of the hole through the knob. $\mathbf{b}$ right: deeper saggital scan further into the mirror subsurface showing interesting density differences and irregularities in the metal. Note that not all the mirror was able to be scanned-hence the missing section bottom left
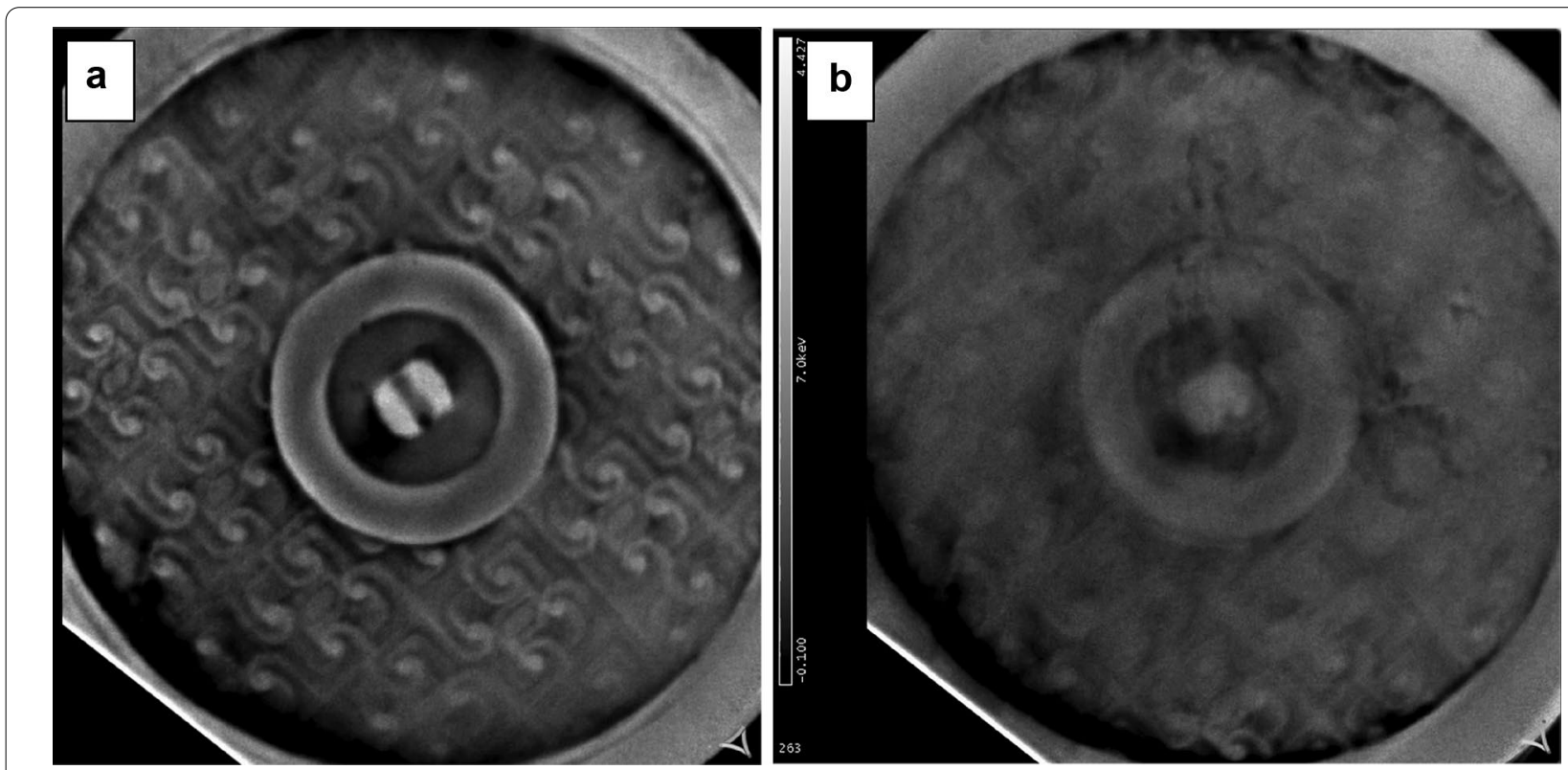

Fig. 17 a Top surface of mirror 1. The hole through the knob is well oriented. b Sub-surface saggital MARS imagery again showing localised density differences in the underlying metal alloy

\section{Infrared spectroscopy}

An ADS portable, high-resolution, near-infrared (NIR) spectroradiometer (model A122320) from the PSML at HKU was used in its $3 \mathrm{~mm}$ fibre-optic probe configuration to perform contact spectroscopy of the green corrosion region on the front surface of mirror 3 as shown in Fig. 11 over the wavelength range 1.8 to 2.4 microns at a resolution of $\sim 6$ nanometres. The resultant NIR spectroscopic results from this test are shown in Fig. 19. The radiance data were calibrated against a 


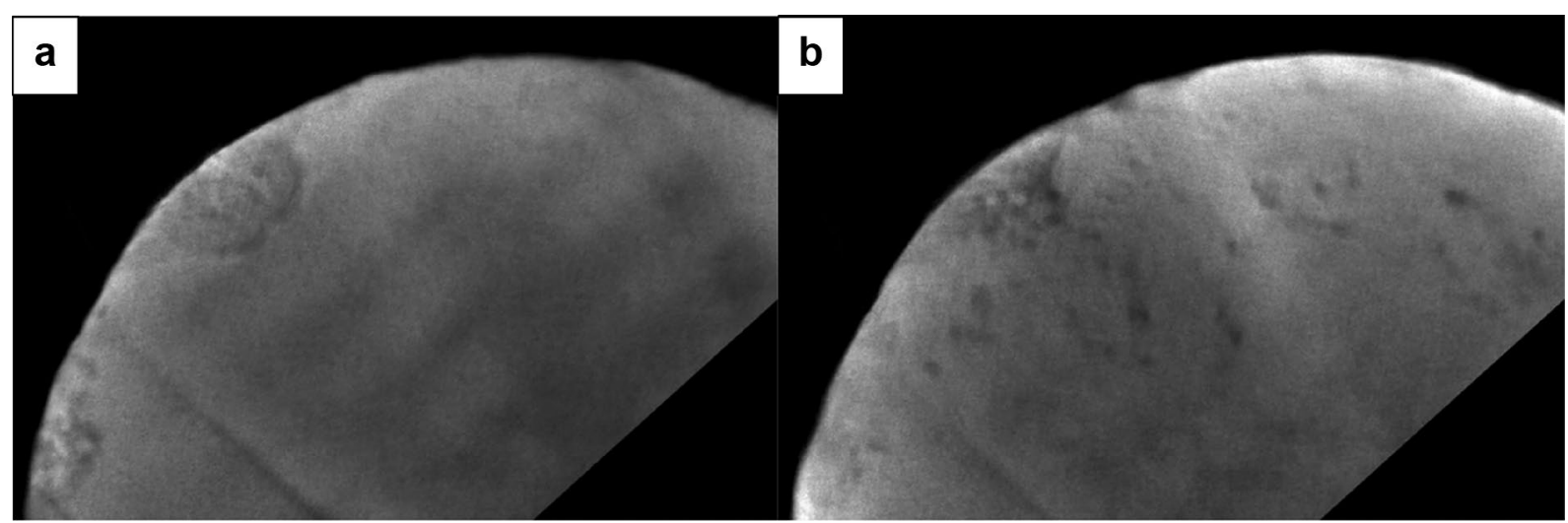

Fig. 18 a and $\mathbf{b}$ Saggital scans through part of mirror 4 showing density irregularities and in this case likely corrosion effects

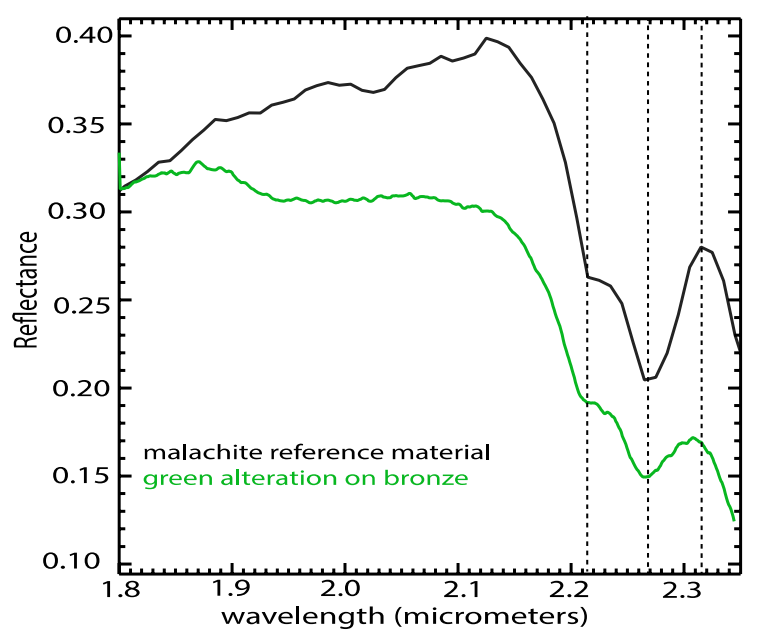

Fig. 19 NIR spectroradiometry of the green corrosion product for mirror 3 shown in Fig. 11. This formally confirms its identification as malachite

white reflectance standard to produce calibrated reflectance values. The reflectance spectrum is compared to a calibrated reflectance spectrum of malachite from the United States Geological Survey spectral library. There is excellent agreement between these spectra. The base bronze alloy and red cuprite corrosion have no spectral features in this wavelength range allowing purer identification. The malachite is distinct from other carbonate minerals by its indicative green colour and the clear $\mathrm{C}-\mathrm{O}$ absorptions located near 2.27 microns. This NIR analysis confirms the identification of this green corrosion product formally as malachite, as already inferred from simple visual inspection and from the separate Polarised Light Microscopy.

\section{Chemical solubility spot testing}

Solubility spot testing across each mirror was the last process applied as part of this forensic investigation. Three chemical solvents were used: ethanol, acetone and turpentine (paint thinner). Here the intention was to see if there was any evidence for any acrylic or oil based paint or adhesive application of "false" patina to any of these mirrors. If so then application of these chemicals would dissolve any such constituents. Small cotton swabs were used to apply each solvent in turn to each mirror. Several regions were chosen on each mirror targeting the various corrosion products and surfaces evident. In no case was any obvious dissolving of any surface noticed and the cotton swabs remained clean with no discolouration.

\section{Discussion}

Four Chinese bronze mirrors nominally dated to the Warring States (mirrors $1 \& 2$ ), Han (mirror 3) and Song (mirror 4) dynasties have been carefully assessed and evaluated. Close examination and scientific surface investigation and application of various forensic testing processes was employed. Different microscopic corrosion morphology and features, including archaeological, have been noted. The wide differentiation in corrosion characteristics evident are likely caused by the strong variations in bronze alloy composition found from surface pXRF, together with their burial histories and subsequent cleaning, handling and curation treatments each has been subjected to.

Mirrors 1 and 2 share certain common features and both have black/dark green patinas, particularly extensive on mirror 2 . This is quite a common feature for mirrors of the Warring States period. They also both have surface pitting as well as residual corrosion. The corrosion from the pits was identified to be copper hydroxide, an unstable middle-stage mineral. It is possible much of 
the original corrosion has been removed by strong abrasive cleaning as evidenced by the surface scratches seen on the shiny green patina remaining in places on mirror 1 and the chromium oxide residue found on both of these mirrors that in itself could have created some of the surface pitting seen. Unfortunately, no photomicrographs on similar corrosion phenomenon on archaeological mirrors has been published which could help to determine if the surface pitting is a feature of natural occurrence or if it is caused by a later corrosive agent used in cleaning. Since these two mirrors were reportedly acquired from the same source and likely in attempts to render them more aesthetically appealing, the original trigger of the remaining visible corrosion remains unknown. However, for mirror 1 there is a thick layer ( 200 microns) of light green residual patination present at many locations on the reverse patterned side of the mirror.

The distinct surface layer compared to matt metal underneath on mirror 3 is also recorded by other scholars on archaeological Han mirrors [28] and as shown on the excavated roman brooch in Fig. 3. The green corrosion on mirrors 3 and 4 were identified to be natural formed malachite and atacamite respectively by both PLM and infrared spectroradiometry. In both these cases there is also important residual archaeology present.

The observed $\mathrm{Cu}-\mathrm{Sn}-\mathrm{Pb}$ ratios revealed by pXRF for mirrors 1,3 and 4 fall into the range of published data from archaeologically excavated and provenanced mirrors. This is not the case for mirror 2 which has an unusually high lead content. The MARS X-ray tomography has revealed there is no pattern under the jade annulus for mirror 3 but there are inhomogeneities in the subsurface metal alloy. Such imperfections are also seen in the bodies of mirrors 1 and 4 but not in mirror 2. Mirrors 1 and 2 do not have any evidence for residual mercury.

In summary, the motif patterns on mirrors 1 and 2 are the Warring States. However, regarding to surface deterioration and copper alloy, mirror 2 in particular presents more questions on the authenticity and treatment history. The key to answer these questions is a detailed scientific analysis on the corrosion and to compare the results to modern reproductions and fakes treated by chemicals [35]. The coincidence of the same corrosion product, copper hydroxide, on both mirrors 1 and 2 points to the possibility of robust chemical and abrasive cleaning, and thereafter an astonishing similarity in the subsequent deterioration rate of their reflective surfaces, although the copper alloy in them are quite different. There is no assumption they have come from the same archaeological site only that they have been treated later in a similar way. The corrosion on the reflective surfaces of mirrors 1 and 2 is likely of recent origin. The patterned reverse sides of mirrors 1 and 2 are very different however, with mirror 1 retaining a very thick ( 200 micron) green patina in several major areas. Taking all this evidence together we consider mirror 2 to be a good quality modern reproduction but mirror 1 has sufficient combined evidential indicators to indicate likely antiquity, i.e.: (i) a very thick green patina on the reverse. It is very hard to create such a thick patina artificially and solvent spot tests show it is not "glued on" or paint etc.; (ii) compatible design and metallurgy for the period; (iii) imperfections seen in the bronze sub-surface as shown by X-ray tomography not seen in modern reproductions.

Mirror 3 has trace archaeological evidence of a burial history due to naturally formed malachite and the residual encrustations on the annular jade attachment which is not affixed with any modern adhesive. Such jade inserts on bronze mirrors are exceptionally rare with only a few examples known. One example can be seen in the collection of the Fogg Art Museum, Harvard University, in Hai-Wai Yi-Chen: Chinese Art in Overseas Collections, Bronze I [31, p. 171]. Although it possible that the jade annulus was added to this mirror later its iconography is typically of the Warring States. If so this is an older jade of this common $b i$-disk form that had a mirror made specifically for it in the Han period given the mirror itself is unusually small. Credence to this possibility is provided by the X-ray tomography that shows there is no pattern on the mirror under the jade annulus. Lack of a pattern here would be extremely unusual if the jade was added later. Jade is extremely durable and was passed down and re-used in antiquity. The antiquity of mirror 3 therefore seems assured. Mirror 4 is typologically dated to the Song dynasty and apart from compatible alloy composition and corrosion also has multiple, interesting archaeological trace evidence including textile pseudomorphs, insect shells and incorporated "charcoal" inclusions. It was perhaps unearthed in northern China and its antiquity is also assured.

\section{Conclusions}

Authenticity of antiquities is a perennial and sensitive problem with many associated ethical and historical implications. The question of authenticity is not just for cultural values that may be inherent in the objects under consideration but because in museums and institutional collections many artifacts do not have any associated or reliable provenance. Alternative means of evaluating them are needed. If physical sampling was allowed, together with analytical and metallographic analysis, the authenticity of bronze antiquities for example can usually be straightforwardly determined. Only non-invasive techniques can be applied for most artifacts housed in museums and reputable collections. Occasionally very small discrete samples can be taken. For these particular 
mirrors it was not allowed to cut-off a piece of metal for metallographic analysis. However, through the careful application of various forensic processes, together with the associated technologies as described in this article, and within the context of the accompanying literature review on their historic perspective, it is possible to make evidence based, scientifically supported assessments and evaluations that will stand up to objective scrutiny. Important conclusions have been drawn based on this generic, multi-facetted, approach with no preconceptions as to object origins.

\section{Supplementary Information}

The online version contains supplementary material available at https://doi. org/10.1186/s40494-021-00496-2.

Additional file 1: Table S1. Elemental abundances for both the reflective and knob side surfaces of the 4 mirrors as provided by $X$-ray fluorescence measurements. Note the trace mercury found on mirrors 3 and 4 and the Chromium found on mirrors 1 and 2 from ancient and modern treatments respectively.

\section{Abbreviations}

UV: Ultraviolet; NIR: Near-infrared; pXRF: Portable X-ray florescence spectroscopy; PLM: Polarized light microscopy.

\section{Acknowledgements}

The authors would like to express thanks to the technical support from the Architectural Conservation Laboratory in Architectural Conservation Programme in Faculty of Architecture, HKU. We would also like to thank both Dr. Leiza va den Broeke and Dr Vince Vardhanabhuti from the department of Diagnostic Radiology from the HKU faculty of medicine for their excellent support and advice with the MARS X-ray tomography. Finally we would also like to thank Dr Joseph Michalski from the Planetary Spectroscopy and Mineralogy Laboratory (PSML) at HKU for help with the Infrared Spectroradiometry measurements and provision of Fig. 19.

\section{Authors' contributions}

Tests and data interpretation and evaluations were jointly carried out by the first and second corresponding author. The manuscript was jointly written by the first and corresponding authors. All authors read and approved the final manuscript.

\section{Funding}

A HKU University Grants Council Teaching \& Learning Grant Number HKU-3 in the 2016-2019 triennium entitled: "Capitalizing on Hong Kong's Position in the Art World: An Innovative Platform for Objects Based Science and Art Learning with a World Class Collaborative Incubator for Future Educational Teaching Resources" supported this research.

\section{Availability of data and materials}

The dataset generated from this study is stored at HKU and is available from the corresponding author on reasonable request.

\section{Competing interests}

The authors declare that there are no known conflicts of interest associate with this publication and there has been no financial support for this work that could have influenced its outcome.

\section{Author details}

${ }^{1}$ Architectural Conservation Laboratory, Faculty of Architecture, The University of Hong Kong, Hong Kong, SAR, China. ${ }^{2}$ Physics Department, Faculty of Science, CYM Physics Building, The University of Hong Kong, Hong Kong, SAR,
China. ${ }^{3}$ The Laboratory for Space Research, The University of Hong Kong, Hong Kong, SAR, China.

Received: 5 November 2020 Accepted: 5 February 2021

Published online: 25 February 2021

\section{References}

1. Liang SC. General discussions on the study of ancient mirrors. Cont Mag. 1952;5(5):190 (in Chinese).

2. Qiu SJ. Chinese antiques in general-bronze mirror. 1st ed. Hefei: Huangshan Shushe; 1995 (in Chinese).

3. Zhang C. Bronze luminescence: bronze mirror collections from the present-past dwelling. Taipei: Artist Press; 2015 (in Chinese).

4. The first discovery of ancient Chinese mirror manufacturing workshop. 2013;62(5):458. (in Chinese).

5. Bai YX. On the two traditions of the bronze mirror casting techniques in East Asia. Chin Archaeol. 2011;11:176-82.

6. Chase W, Lee J. China house gallery. Ancient Chinese bronze art: casting the precious sacral vessel. New York: China House Gallery China Institute In America; 1991.

7. Barnard N. Bronze casting and bronze alloys in ancient China (Monumenta serica monograph series). Canberra: Australian National University; 1961.

8. Grissom CA. Zinc Sculpture in America: 1850-1950. Plainsboro: Associated University Presses; 2009.

9. Kong XX, Liu YM. Ancient Chinese bronze mirrors. 1st ed. Beijing: Wenwu press; 1984 (in Chinese).

10. Dong YW. Relationship between copper alloy and section geometry of ancient Chinese bronze mirrors. J Natl Mus China. 2000;02:114-21 (in Chinese).

11. Sun H, Niu Z, Wang C, Yuan B. Scientific analysis of an ancient bronze mirror dating of Han Dynasty. Adv Mater Res. 2011;337:743-6.

12. Yang J, Li YX, Zhu ZG. Studies on the bronzes unearthed from Xitun Cemetery in Yanqing, Beijing. China Cult Herit Sci Res. 2012;03:76-80 (in Chinese).

13. Liu YX, Chen KL, Mei JJ, Sun WG, Shao AD. Scientific study on bronze mirrors unearthed from Tomb of Xinfeng dated to Qin dynasty, Lintong, Shaanxi province. Zhongyuan Relics. 2015;2015(04):111-5 (in Chinese)

14. Nan PH, Tian JM, Wang XY, Li ZM. Conservation and restoration of one Han Dynasty thin bronze mirror excavated form M24 of Liushugou Cemetery in Hubei Province. Sci Conserv Archaeol. 2016;03:78-85 (in Chinese).

15. He TK, Song YQ. Surface analysis of bronze mirror unearthed from Linxi. Sichuan Relics. 1994;06:70-7 (in Chinese).

16. Yang YW. Cleaning, analysis and restoration of bronze mirrors dated to Song and Jin dynasty. World Antiquity. 2012;04:77-80 (in Chinese).

17. Lou SH, Zhou SL. The scientific analysis of the bronze mirror ornamented with gold from the Kele ruins in Guizhou Hezhang. 2009;01:37-43 (in Chinese).

18. Chinese Text Project: Xiuwuxun by Huai Nanz https://ctext.org/huainanzi/ xiu-wu-xun/zh?searchu,No.8. Shanghai:China (in Chinese).

19. Song YX. 1587-Tian Gong Tai Wu [electronic resource]. Shanghai: Sinology Organization World Book Printing Bureau; 1936 (in Chinese).

20. Costello S. An Investigation of Early Chinese Bronze Mirrors at the Harvard University Art Museums [thesis (certificate in conservation)]. Unpublished. Straus Center for Conservation and Technical Studies. 2005.

21. Eastaugh N. Pigment compendium: a dictionary and optical microscopy of historical pigments. Amsterdam: Butterworth-Heinemann; 2008.

22. CAMEO. Website: www.cameo.mfa.org. Accessed July 12, 2020.

23. Scott DA. Copper and bronze in art: corrosion, colorants, conservation. Los Angeles: Getty Conservation Institute; 2002.

24. Casini A, Radicati B, Stefani L, Bellucci R. A multispectral scanning device for reflectance and colour measurements: An Application to the Croce di Rosano. Art 2002: 7th International Conference on Non- destructive Testing and Microanalysis for the Diagnostics and Conservation of the Cultural and Environmental heritage; 2002. Antwerp, Belgium.

25. Ma QL, Scott DA. Gold and silver gilding techniques in the Western Han Dynasty of China. Sci Conserv Archaeol. 2004;16(2):21-6. 
26. Scott AD. Bronze disease: a review of some chemical problems and the role of relative humidity. J Am Inst Conserv. 1990;29(2):193-206.

27. Wang C, Lu B, Zuo J, Zhang S, Tan S, Suzuki M, Chase WT. Structural and elemental analysis on the nanocrystalline $\mathrm{SnO}_{2}$ in the surface of ancient Chinese black mirrors. Nanostruct Mater. 1995;5(4):489-96.

28. Chemical and structural information of bronze mirror dated to Han dynasty. Archaeology. 1988;04:371-376 (in Chinese)

29. He TK. Surface analysis of bronze mirror unearthed from Echeng. Stud Hist Nat Sci. 1987;02:175-87 (in Chinese).

30. Liang JF, Wang ZK, Zhao XC. Using portable analytical devices to document Tomb M4 dated to Western Zhou Dynasty, Shi Gu Shan, Baoji County, Shaanxi, China. Cult Relics. 2016;1:88-96.

31. Taipei the National Palace Museum. Collection of the Fogg Art Museum Harvard University, in Hai-Wai Yi-Chen: Chinese Art in Overseas Collections, Bronze I.1992;168-171

32. Pope JA, Rutherford JG. The freer Chinese bronzes, vol. II. Washington: Smithsonian Institution; 1967.

33. Shanxi Museum, Museum Shanxi. Conservation and scientific studies on bronzes in Shanxi Museum. 1st ed. Beijing: China Science Publishing \& Media Ltd: 2016. p. 173.

34. Li XJ, Martinón-Torres M, Meeks ND, Xia Y, Zhao K. Inscriptions, filing, grinding and polishing marks on the bronze weapons from the Qin Terracotta army in China. J Archaeol Sci. 2011;38(3):492-501.
35. Li JS. Research on bronze corrosion and fake patination. Identif Apprec Cult Relics. 2013;02:70-7 (in Chinese).

36. He TK. Copper alloy of bronze mirrors dated to Song Dynasty. Sichuan Relics. 1990;03:74-9 (in Chinese).

37. Luo W, Li T. The use of chromium minerals in the 4th-3rd century BC China? A preliminary study of a bronze Pan unearthed from Jiuliandun Graves, Hubei Province, central southern China. J Raman Spectrosc. 2012;43(2):303-6.

38. He TK. Surface analysis of bronzes containing chromium. Archaeolgoy. 1996;07:71-5 (in Chinese).

39. Ma ZZ, Han RF. Chromium oxidization layer on bronze arrow heads unearthed from Terra Totta Warriors and Horses pit of First Emperor Qin Univ Chem. 1988;3(3):57-60 (in Chinese)

40. Martinón-Torres M, Li XZ, Xia Y, Benzonelli A, Bevan A, Ma ST, et al. Surface chromium on Terracotta Army bronze weapons is neither an ancient anti-rust treatment nor the reason for their good preservation. Sci Rep. 2019;9(1):1-11.

\section{Publisher's Note}

Springer Nature remains neutral with regard to jurisdictional claims in published maps and institutional affiliations.

\section{Submit your manuscript to a SpringerOpen ${ }^{\circ}$ journal and benefit from:}

- Convenient online submission

- Rigorous peer review

- Open access: articles freely available online

- High visibility within the field

- Retaining the copyright to your article

Submit your next manuscript at $\boldsymbol{\nabla}$ springeropen.com 